\title{
Chemotherapy followed by anti-CD137 mAb immunotherapy improves disease control in a mouse myeloma model
}

\author{
Camille Guillerey, ${ }^{1,2,3}$ Kyohei Nakamura, ${ }^{1}$ Andrea C. Pichler, ${ }^{4}$ Deborah Barkauskas, ${ }^{1}$ \\ Sophie Krumeich, ${ }^{1}$ Kimberley Stannard, ${ }^{1}$ Kim Miles, ${ }^{1}$ Heidi Harjunpää, ${ }^{2,5}$ Yuan Yu, ${ }^{1}$ Mika Casey, ${ }^{1}$ \\ Alina I. Doban, ${ }^{6}$ Mircea Lazar, ${ }^{7}$ Gunter Hartel, ${ }^{8}$ David Smith, ${ }^{8}$ Slavica Vuckovic, ${ }^{9,10}$ \\ Michele W.L. Teng, ${ }^{5}$ P. Leif Bergsagel, ${ }^{11}$ Marta Chesi, ${ }^{11}$ Geoffrey R. Hill, ${ }^{9,12}$ Ludovic Martinet, ${ }^{4}$ \\ and Mark J. Smyth ${ }^{1,2}$ \\ IImmunology in Cancer and Infection Laboratory, QIMR Berghofer Medical Research Institute, Herston, Queensland, \\ Australia. ${ }^{2}$ School of Medicine, The University of Queensland, Herston, Queensland, Australia. ${ }^{3}$ Cancer Immunotherapies \\ Laboratory, Mater Research Institute, The University of Queensland, Translational Research Institute, Woolloongabba, \\ Queensland, Australia. ${ }^{4}$ Cancer Research Center of Toulouse, INSERM UMR 1037, Toulouse, France. ${ }^{5}$ Cancer \\ Immunoregulation and Immunotherapy Laboratory, QIMR Berghofer Medical Research Institute, Herston, Queensland, \\ Australia. ${ }^{6} \mathrm{ASML}$ Netherlands B.V., Veldhoven, Netherlands. ${ }^{7}$ Department of Electrical Engineering, Eindhoven \\ University of Technology, Eindhoven, Netherlands. ${ }^{8}$ Statistics Unit and ${ }^{9}$ Bone Marrow Transplantation Laboratory, QIMR \\ Berghofer Medical Research Institute, Herston, Queensland, Australia. ${ }^{10}$ Multiple Myeloma Research Group, Institute of \\ Haematology, Royal Prince Alfred Hospital, Camperdown, New South Wales, Australia. "Comprehensive Cancer Center, \\ Mayo Clinic, Scottsdale, Arizona, USA. ${ }^{12}$ Fred Hutchinson Cancer Research Center, Seattle, Washington, USA.
}

Immunotherapy holds promise for patients with multiple myeloma (MM), but little is known about how MM-induced immunosuppression influences response to therapy. Here, we investigated the impact of disease progression on immunotherapy efficacy in the $\mathrm{Vk}^{*} \mathrm{MYC}$ mouse model. Treatment with agonistic anti-CD137 (4-1BB) mAbs efficiently protected mice when administered early but failed to contain MM growth when delayed more than 3 weeks after Vk*MYC tumor cell challenge. The quality of the $C D 8^{+} T$ cell response to $C D 137$ stimulation was not altered by the presence of $M M$, but $\mathrm{CD8}^{+} \mathrm{T}$ cell numbers were profoundly reduced at the time of treatment. Our data suggest that an insufficient ratio of CD8 ${ }^{+} \mathrm{T}$ cells to MM cells (CD8/MM ratio) accounts for the loss of anti-CD137 mAb efficacy. We established serum M-protein levels prior to therapy as a predictive factor of response. Moreover, we developed an in silico model to capture the dynamic interactions between $\mathrm{CD}^{+} \mathrm{T}$ cells and MM cells. Finally, we explored two methods to improve the CD8/MM ratio: anti-CD137 mAb immunotherapy combined with Treg depletion or administered after chemotherapy treatment with cyclophosphamide or melphalan efficiently reduced $\mathrm{MM}$ burden and prolonged survival. Together, our data indicate that consolidation treatment with anti-CD137 mAbs might prevent MM relapse.

Conflict of interest: MJS has research agreements with Bristol-Myers Squibb, Tizona Therapeutics, and Aduro Biotech.

Copyright: @ 2019 American Society for Clinical Investigation

Submitted: November 1, 2018 Accepted: June 5, 2019 Published: June 13, 2019

Reference information: /CI Insight. 2019;4(14):e125932. https://doi. org/10.1172/jci.insight.125932.

\section{Introduction}

Multiple myeloma (MM) is a hematological malignancy in which clonal plasma cells secreting monoclonal proteins (M-proteins) proliferate in the bone marrow (BM). Standard treatment options include autologous stem cell transplantation for eligible patients, as well as alkylating agents such as cyclophosphamide, proteasome inhibitors such as bortezomib, and immunomodulatory drugs (IMiDs; ref. 1). Despite high response rates to standard therapies, most MM patients relapse and eventually succumb to the disease. Therefore, new therapeutic options with different mechanisms of action are urgently needed to eradicate residual disease and achieve long-term remission.

A variety of immune-based therapies are now being explored, with the potential to overcome MM cell resistance to conventional drugs (2). Elotozumab (anti-SLAMF7) and daratumumab (anti-CD38) are mAbs that were FDA approved in 2015 for the treatment of patients with relapsed/refractory MM (3). These mAbs target molecules expressed on MM cells and exert their antitumor effect through multiple 
mechanisms including immune modulation. Many other immune-based strategies are currently in development, such as bispecific antibodies, infusions of ex vivo expanded/activated autologous $\mathrm{T}$ or NK cells, T cell receptor-modified (TCR-modified) T cells, and chimeric antigen-receptor T and NK cells (4). Immune checkpoint inhibition is also considered for the treatment of MM. A phase I clinical study reported disease stabilization, but no objective response, in relapsed/refractory MM patients treated with single-agent antiprogrammed cell death protein 1 (anti-PD-1) blocking mAb nivolumab (5). Moreover, in spite of encouraging response rates, a phase II clinical study examining the anti-PD-1 mAb pembrolizumab in combination with IMiDs was terminated due to increased risk of severe adverse events (6).

Agonistic mAbs targeting costimulatory molecules represent an alternative to checkpoint inhibitors (7). CD137 (4-1BB) is a costimulatory molecule expressed on activated T and NK cells as well as antigen-presenting cells and endothelial cells (8). Upon ligation, CD137 signals through NF- $\mathrm{B}$ and the MAPK cascade to promote cell survival, proliferation, and enhanced effector functions (9). Recent evidence indicates that CD137 costimulation augments the mitochondrial mass of $\mathrm{CD}^{+} \mathrm{T}$ cells (10). CD137 costimulation also induces chromatin remodeling and thereby imprints long-term changes in CD8 ${ }^{+} \mathrm{T}$ cells (11).

Agonistic anti-CD137 mAbs promote Th1-type responses and have shown activity in a number of syngeneic mouse tumor models, including models of $\mathrm{MM}$ and plasmacytomas $(12,13)$. The antitumor effect of anti-CD137 mAbs in mice generally depends on IFN- $\gamma$ and $\mathrm{CD}^{+} \mathrm{T}$ cells, while CD4 ${ }^{+} \mathrm{T}$ cells and NK cells are either required or dispensable depending on the tumor model (14). Notably, in the Vk* MYC mouse model of $\mathrm{MM}$, anti-CD137 mAb immunotherapy was found to require $\mathrm{CD} 8^{+} \mathrm{T}$ cells and $\mathrm{NK}$ cells but not $\mathrm{CD} 4^{+} \mathrm{T}$ cells (12). Furthermore, recent work highlighted the essential role BATF3-dependent DCs in cross-priming CD8 ${ }^{+}$ $\mathrm{T}$ cells specific to tumor antigens and their importance for the response to anti-CD137 mAb therapy (15).

Two fully humanized anti-CD137 mAbs have entered clinical trials: urelumab (BMS-663513) and utomilumab (PF-05082566). Doses of acceptable toxicities had to be defined for urelumab, as this $\mathrm{mAb}$ had caused severe liver damage at high doses (16). By contrast, only mild toxicities were observed with utomilumab $(17,18)$. In phase I/II clinical trials, both mAbs have shown signs of immunologic activity associated with an IFN response $(16,17)$. Therefore, anti-CD137 mAbs hold promise for the treatment of a broad range of malignancies, including $\mathrm{MM}$, for which urelumab is now being assessed in combination with elotuzumab (NCT02252263).

Since host-related immunodeficiency is frequently observed in MM (19, 20), a better understanding of how MM-induced immunosuppression affects immunotherapy efficacy is needed to define the best therapeutic conditions and to identify prognostic markers. In this study, we investigated the factors determining the efficacy of agonistic anti-CD137 mAb immunotherapy in the Vk* MYC model of mouse MM. We combined in vivo, ex vivo, and in silico analyses to investigate the dynamic interactions between $\mathrm{CD}^{+} \mathrm{T}$ cells and $\mathrm{MM}$ cells in the BM of anti-CD137 mAb-treated mice. Overall, our data indicate that single-agent anti-CD137 mAb therapy is only efficient against low MM burden. Yet we show that at advanced disease stages, therapeutic efficacy of anti-CD137 mAb can be achieved by releasing immunosuppression through Treg depletion or by debulking the tumor through chemotherapy.

\section{Results}

Early anti-CD137 mAb treatment induces potent effector $T$ cell responses and protects mice against MM with negligible toxicity. To evaluate the efficacy of anti-CD137 mAbs against MM, we challenged C57BL/6 WT mice with Vk12653 (Vk*MYC) MM cells, followed by 2-week treatment with anti-CD137 mAbs starting at 2 weeks after tumor inoculation. Anti-CD137 mAb treatment significantly prolonged the survival of MM-challenged mice, with $68 \%$ (13 of 19 ) of the anti-CD137 mAb-treated mice becoming long-term survivors (experiment ended at 140 days) (Figure 1A). Moreover, monoclonal gammopathy at week 5 after $\mathrm{Vk}^{*} \mathrm{MYC}$ cell injection was clearly reduced in anti-CD137 mAb-treated mice (Figure 1B). Mice treated with anti-CD137 mAbs harbored significantly reduced numbers of $\mathrm{MM}$ cells (Figure $1 \mathrm{C}$ ) and increased numbers of $\mathrm{CD} 8^{+} \mathrm{T}$ cells and FoxP3-CD4+ Th cells in the BM and spleen (Figure 1, D and E). These data confirm our previous findings that anti-CD137 mAbs induce massive T cell expansion and provide long-term protection against MM (12).

To gain further insight into the quality of the $\mathrm{T}$ cell response induced following anti-CD137 $\mathrm{mAb}$ treatment, we analyzed cytokine production by intracellular staining. We found that anti-CD137 $\mathrm{mAb}$ treatment increased the percentage of IFN- $\gamma-$ and TNF-producing $\mathrm{CD} 4^{+}$and $\mathrm{CD} 8^{+} \mathrm{T}$ cells in the $\mathrm{BM}$ and spleen (Figure 2, A and B). We also observed an increase in IL-10-producing T cells, with $\mathrm{BM} \mathrm{CD} 4^{+} \mathrm{T}$ cells being the most important IL-10 producers. Moreover, we analyzed the memory 
A

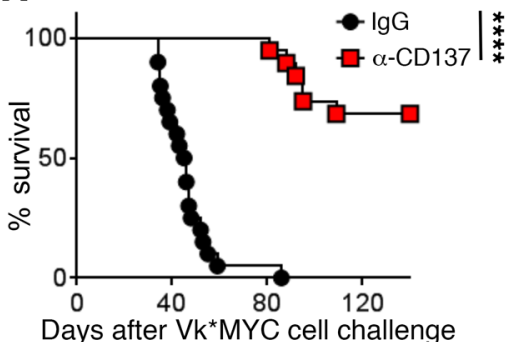

Days after VkMYC cell challenge
B

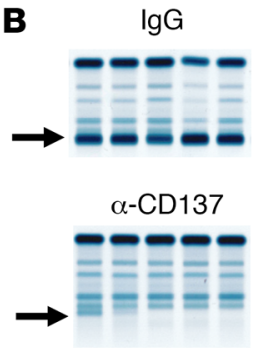

C
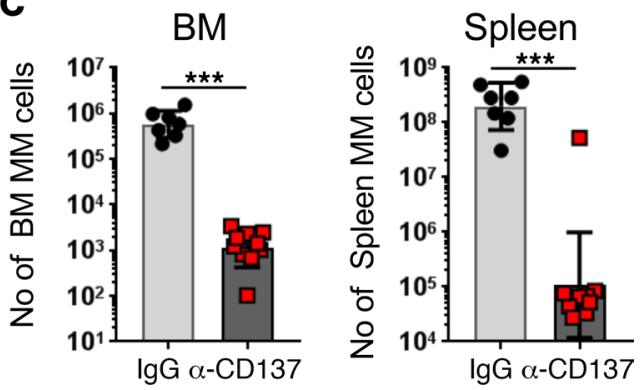

D

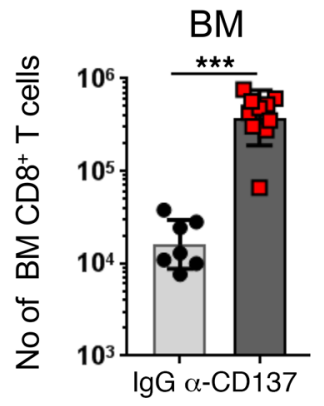

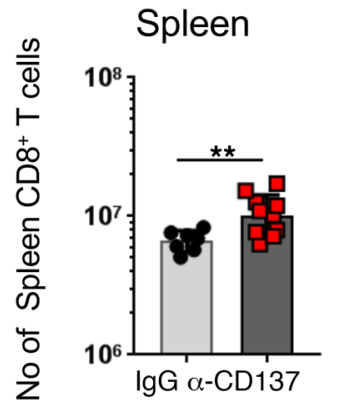
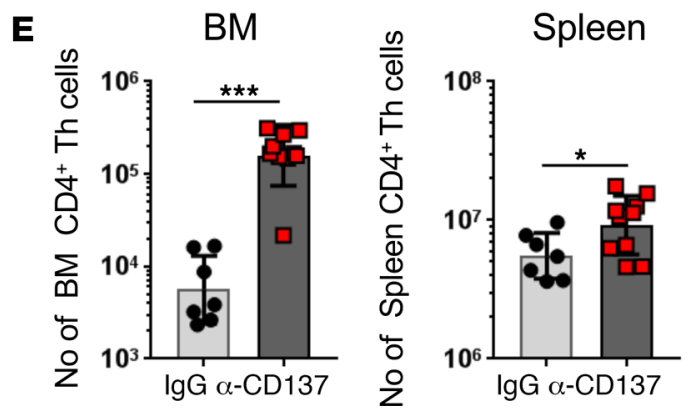

Figure 1. Early anti-CD137 mAb treatment increases T cell numbers and provides long-term protection against MM. C57BL/6 WT mice were challenged i.v. with $2 \times 10^{6}$ Vk12653 (Vk* MYC) cells, and after 2 weeks, mice received a 2-week anti-CD137 mAb or control rat lgG2a (IgG) treatment. (A) Survival was monitored over time. Kaplan-Meier plot; data were pooled from 2 independent experiments, each with $n=9-10$ mice per group and analyzed with a log-rank test. (B) Representative serum electrophoresis gel at week 5 after $\mathbf{K}^{*} \mathrm{MYC}$ cell challenge. Arrows indicate the M-protein bands. (C-E) Numbers of (C) malignant CD155 $5^{+}$plasma cells (MM cells), (D) CD8 ${ }^{+}$T cells, and (E) FoxP3-CD4+ Th cells in the spleen and BM were determined by flow cytometry at week 5 after Vk* MYC cell challenge. Graphs show geometric mean \pm SD of 1 experiment ( $n=7-10$ mice per group) representative of 2 independent experiments. Statistical differences were assessed with a Mann-Whitney $U$ test. ${ }^{*} P<0.05,{ }^{* *} P<0.01,{ }^{* * *} P<0.001,{ }^{* * *} P<0.0001$.

status of $\mathrm{BM} \mathrm{CD} 8^{+} \mathrm{T}$ cells and observed a large increase in $\mathrm{CD} 44^{+} \mathrm{CD} 62 \mathrm{~L}^{-}$effector/effector memory (TEM) cells following anti-CD137 mAb injection into both tumor-naive and MM-bearing mice (Figure 2C and Supplemental Figure 1; supplemental material available online with this article; https://doi. org/10.1172/jci.insight.125932DS1).

As the potent $\mathrm{T}$ cell responses induced by anti-CD137 mAbs may lead to tissue damage, and notably hepatotoxicity (21), we measured serum levels of the liver enzymes alanine transaminase (ALT) and aspartate transaminase (AST), as well as T cell and tumor cell infiltration of the liver. AST levels were significantly increased in control IgG- but not anti-CD137 mAb-treated mice (Supplemental Figure 2A), probably reflecting liver damage caused by the tumor (Supplemental Figure 2B). The livers of anti-CD137 $\mathrm{mAb}$-treated mice harbored very low numbers of MM cells but showed increased lymphocytic infiltrates, including $\mathrm{CD}^{+} \mathrm{T}$ cells and FoxP3 ${ }^{+}$Tregs (Supplemental Figure 2, B-F). Overall, anti-CD137 mAb-treated mice appeared healthy, and we did not observe obvious external signs of autoimmunity or inflammation. Taken together, these data indicate that anti-CD137 mAbs induce strong effector $\mathrm{T}$ cell responses that efficiently protect mice against $\mathrm{MM}$, with negligible liver damage.

CD137 stimulation induces transient NK cell responses followed by $T$ cell proliferation and IFN- $\gamma$ production. We previously reported that, in the Vk* MYC MM model, therapeutic efficacy of anti-CD137 mAbs requires the presence of both $\mathrm{NK}$ cells and $\mathrm{CD} 8^{+} \mathrm{T}$ cells (12). To gain further insight into the kinetics of lymphocyte responses to CD137 stimulation, tumor-naive WT mice were given a single injection of anti-CD137 mAbs on day 0 , and NK and T cell proliferation and IFN- $\gamma$ production were analyzed in the BM and spleen on days 1, 3, and 7. By day 3 after anti-CD137 mAb injection, NK cell responses had reached their maximum, and we observed a significant increase in the percentages of proliferating and IFN- $\gamma$-producing NK cells when compared with IgG-treated mice (Figure 3, A-D, and Supplemental Figure $3, \mathrm{~A}$ and $\mathrm{B}$ ). By contrast, on day 3 , percentages of proliferative $\mathrm{CD} 4^{+}$and $\mathrm{CD} 8^{+} \mathrm{T}$ cells were only slightly increased in anti-CD137 mAb-treated mice, and there was virtually no change in IFN- $\gamma$ production compared with control IgG-treated mice. However, on day 7, we observed strong T cell proliferation and IFN- $\gamma$ production in mice that had received anti-CD137 mAbs. We also measured systemic levels of 
A Bone marrow
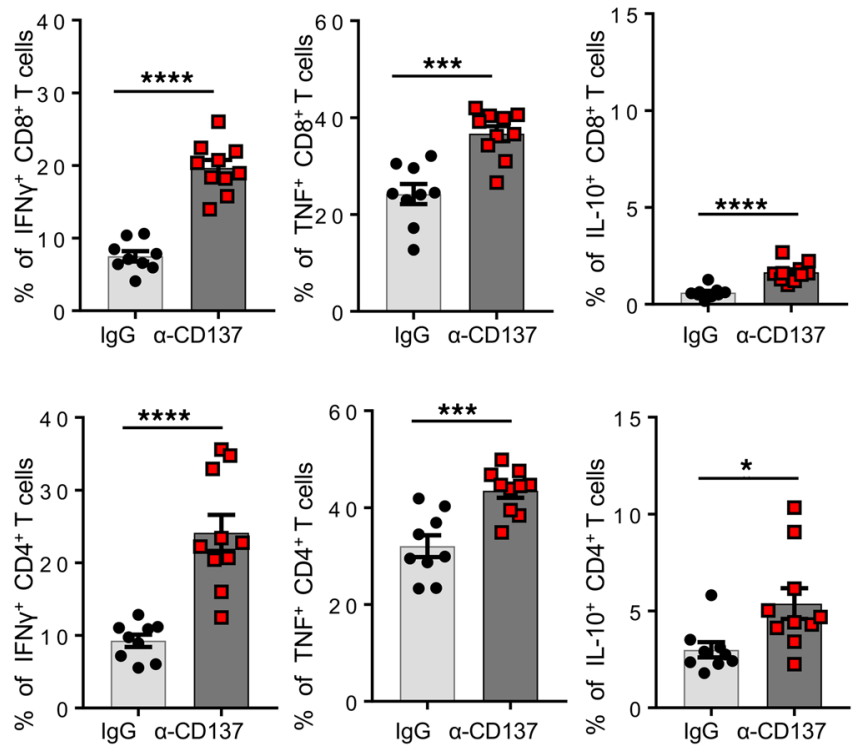

B Spleen
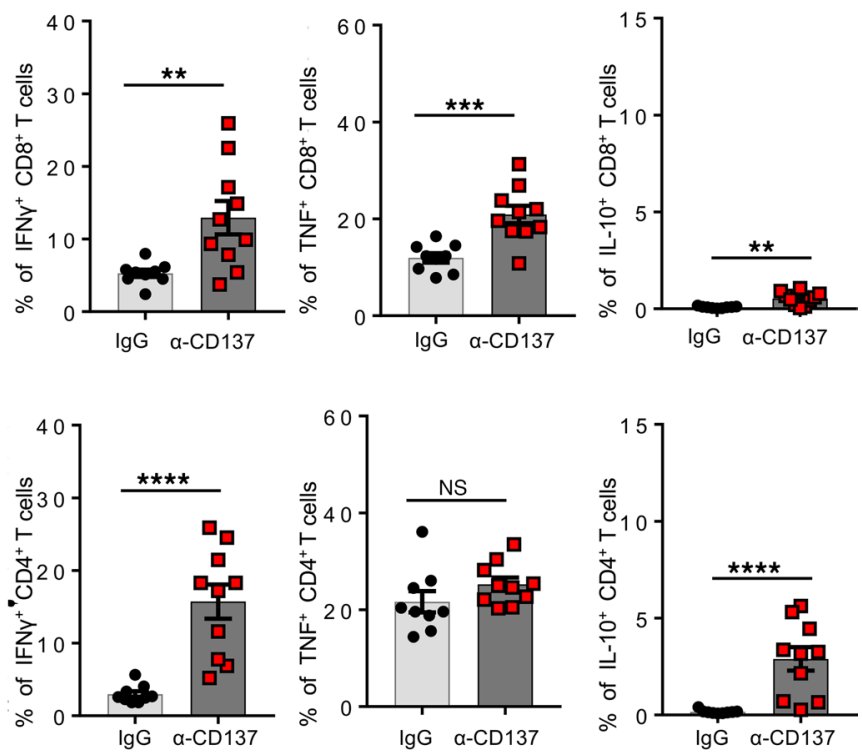

C

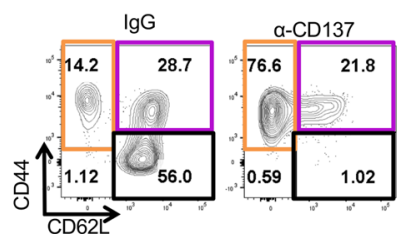

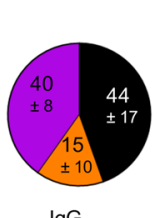

$\lg G$

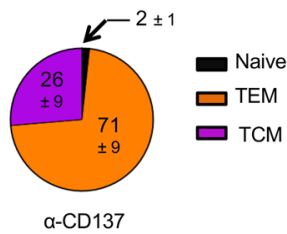

Figure 2. Anti-CD137 mAb treatment induces potent effector T cell responses. WT mice were challenged with Vk* MYC cells, and after 3 weeks, mice received a 2-week anti-CD137 mAb treatment. (A) BM and (B) spleen cells were isolated at week 5 after Vk* MYC cell challenge and cultured with PMA-ionomycin for 2 hours and IFN $-\gamma$, TNF, and IL-10 production by CD4 ${ }^{+}$and $\mathrm{CD} 8^{+} \mathrm{T}$ cells was determined by intracellular staining. Graphs show mean $\pm \mathrm{SEM}$ of one experiment ( $n=9$-10 mice per group) representative of 2 independent experiments. Statistical differences were assessed with a Mann-Whitney $U$ test. ${ }^{*} P<0.05$, ${ }^{* *} P<$ $0.01,{ }^{* *} P<0.001,{ }^{* * *} P<0.0001$. (C) Naive WT mice received a 2-week anti-CD137 mAb treatment, and percentages of naive (CD62L+CD44), effector/effector memory (TEM: CD62 $\mathrm{L}^{-} \mathrm{CD} 44^{+}$), and central memory (TCM: CD62 $\left.\mathrm{L}^{+} \mathrm{CD} 44^{+}\right) \mathrm{BM}$ CD8 ${ }^{+} \mathrm{T}$ cells were analyzed by flow cytometry. Data are shown as representative graph plots (left) and pie charts (right) displaying mean \pm SD of 4 independent experiments, each with $n=2-4$ mice per group.

IFN- $\gamma$ and observed a slight increase on day 7 after CD137 mAb injection (Supplemental Figure 3C). Of note, the magnitude of T cell responses was greater in the BM (Figure 3, A-D) than in the spleen (Supplemental Figure 3, A and B). In agreement with previous reports (22-24), we observed reduced numbers and percentages of NK cells in mice injected with anti-CD137 mAbs (Figure 3, E and F). This decrease was more striking in the spleen than in the BM. We obtained similar results when NK cells were gated either as TCR $\beta^{-} \mathrm{NK} 1.1^{+}$or TCR $\beta^{-} \mathrm{NKp} 46^{+}$cells (data not shown). Together, these data indicate that NK cells are the first lymphocytes to respond to CD137 stimulation, but NK cell responses are transient. By day 7 after anti-CD137 mAb injection, the majority of NK cells had disappeared, while T cells showed robust proliferation and IFN- $\gamma$ production.

IFN- $\gamma$ signaling is required for $C D 8^{+} T$ cell expansion and optimal efficacy of anti-CD137 mAb therapy. To investigate the importance of IFN signaling for $\mathrm{CD}^{+} \mathrm{T}$ responses to $\mathrm{CD} 137$ stimulation, tumor-naive $\mathrm{WT}$, Ifn $\gamma^{-/-}$, and Ifn $\mathrm{r}^{-1-}$ mice received a 2-week anti-CD137 mAb treatment. We observed a large increase in $\mathrm{CD}^{+} \mathrm{T}$ cell numbers in the BM and spleen of anti-CD137 mAb-treated WT mice, whereas $\mathrm{CD} 8^{+} \mathrm{T}$ cell expansion in response to anti-CD137 mAb treatment was compromised in the spleen of Ifn $\gamma^{-/-}$mice and in the BM and spleen of Ifn $\gamma r^{-1-}$ mice (Figure 4A and Supplemental Figure 4A). Yet percentages of $\mathrm{CD}_{4}{ }^{+} \mathrm{CD}^{2} 2 \mathrm{~L}^{-} \mathrm{TEM} \mathrm{CD} 8{ }^{+} \mathrm{T}$ cells were increased in Ifn $\gamma \mathrm{r}^{--}$mice following anti-CD137 $\mathrm{mAb}$ treatment (Supplemental Figure 4B), indicating that, in spite of their limited expansion, $\mathrm{CD}^{+} \mathrm{T}$ cells do respond to CD137 stimulation in the absence of IFN- $\gamma$ signaling. By contrast, anti-CD137 mAb treatment increased the numbers of $\mathrm{BM} \mathrm{CD} 8^{+} \mathrm{T}$ cells in Ifnar ${ }^{--}$mice, indicating that type I IFNs are not essential for CD $8^{+} \mathrm{T}$ expansion following CD137 stimulation (Supplemental Figure 4C). 
A
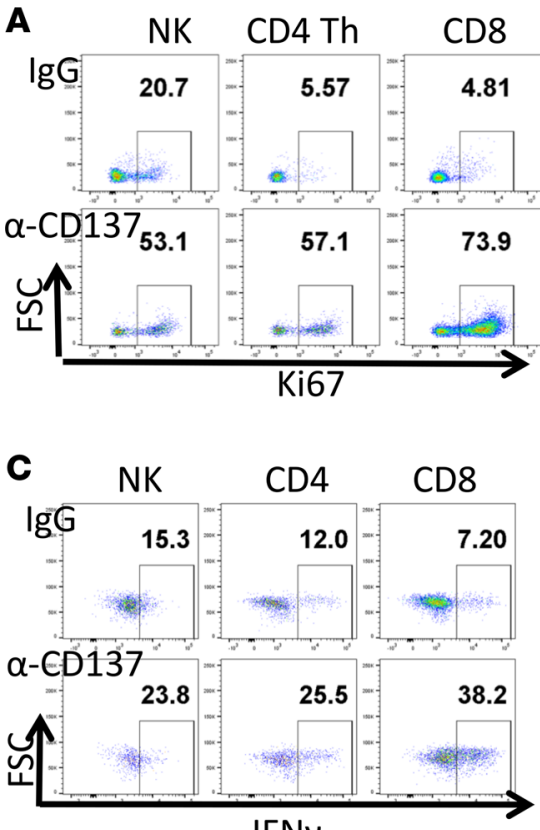

IFNY

\section{B}
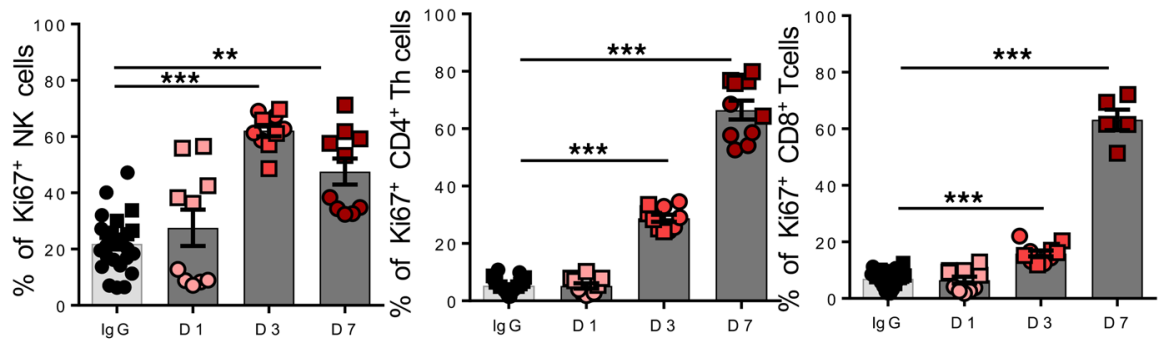

D
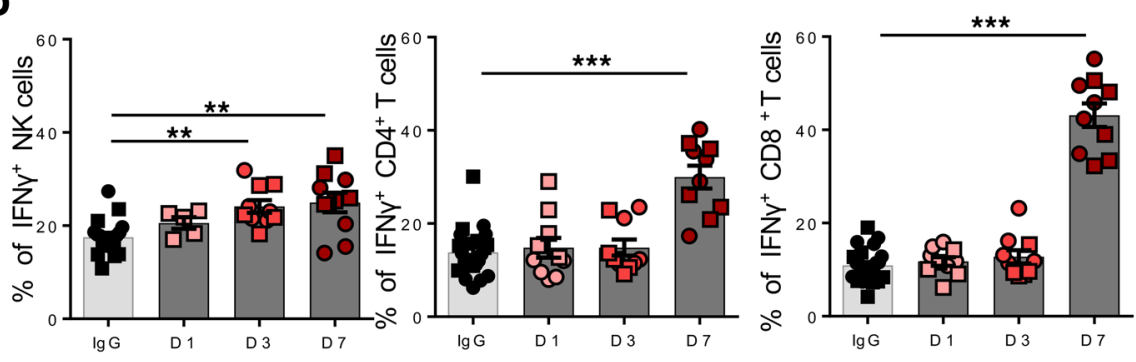

E

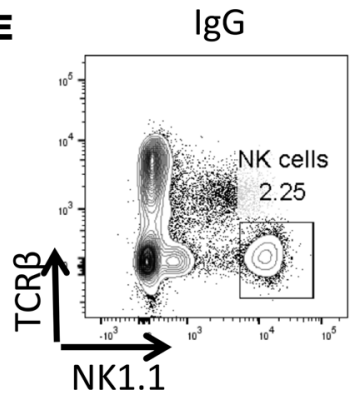

a-CD137

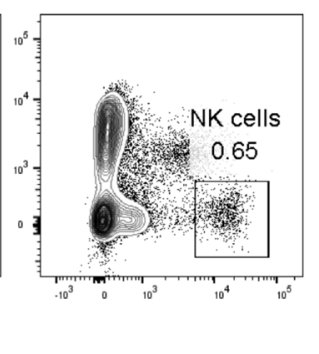

$\mathbf{F}$

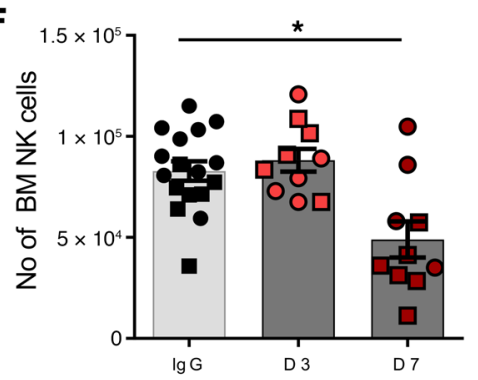

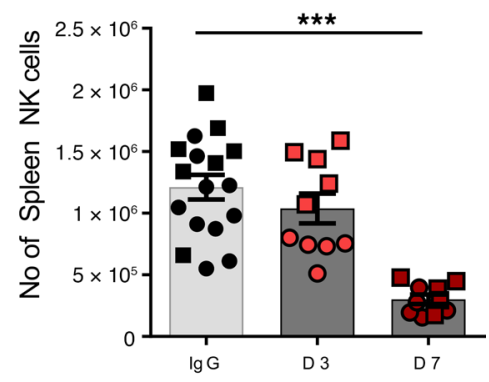

Figure 3. NK and T cells show different kinetics of response to CD137 stimulation. Naive WT mice received a single i.p. injection of $100 \mu$ g anti-CD137 mAbs or control IgG on day 0 , and analysis was performed on days 1, 3, and 7 (D1, D3, and D7). (A and B) Proliferation of BM NK cells (NK), FoxP3- CD4+ cells (CD4 Th), and CD8 ${ }^{+}$T cells (CD8) was assessed by Ki-67 staining. (C and D) Total BM cells were cultured with PMA-ionomycin for 2 hours, and IFN- $\gamma$ production by NK cells, CD4 ${ }^{+} T$ cells, and $C D 8^{+} T$ cells was assessed by intracellular staining. ( $E$ and $\mathbf{F}$ ) NK cell numbers in the spleen and BM were quantified by flow cytometry. Data are shown as (A, C, and E) representative staining on day 7 or (B, D, and F) mean \pm SEM of data from 2 pooled experiments, each with $n=5$ mice per group. Dot plots in E represent data from spleen. Data were analyzed with a Kruskal-Wallis test followed by Dunn's multiple-comparisons post hoc test. ${ }^{*} P<0.05,{ }^{* *} P<0.01,{ }^{* *} P<0.001$.

Next we analyzed the IFN requirement of anti-CD137 mAbs for their anti-MM effect. We observed that the efficacy of anti-CD137 mAbs against MM was compromised in Ifny ${ }^{-1-}$ mice (Figure 4B). Interestingly, lack of treatment efficacy was associated with decreased $\mathrm{CD} 8^{+} \mathrm{T}$ cell numbers in the $\mathrm{BM}$ of anti-CD137 $\mathrm{mAb}$ treated Ifn $\gamma^{--}$compared with WT mice (Figure 4C), as well as increased IL-10 production by CD4+ $\mathrm{T}$ cells (Figure 4, D and E). Of note, anti-CD137 mAb treatment could not be tested in Ifnyr ${ }^{\prime-}$ mice because these mice failed to develop MM when challenged with $\mathrm{Vk}^{*} \mathrm{MYC}$ MM cells (data not shown), probably because of high circulating levels of IFN- $\gamma$ (Supplemental Figure 4D). In agreement with their ability to expand $\mathrm{CD}^{+} \mathrm{T}$ cells in the absence of type I IFN signaling, anti-CD137 mAbs efficiently protected Ifnar ${ }^{\prime-}$ mice against MM (Supplemental Figure 4E). Together, these data demonstrate that IFN- $\gamma$ contributes to $\mathrm{CD} 8^{+} \mathrm{T}$ cell expansion and is essential for efficient anti-CD137 mAb therapy in the $\mathrm{Vk} * \mathrm{MYC}$ mouse model of MM.

Anti-CD137 mAb treatment loses efficacy when delayed more than 3 weeks after $V k^{*} M Y C$ cell challenge. So far, our data established that anti-CD137 mAb treatment efficiently protects against $\mathrm{MM}$ when given at week 2 after $\mathrm{Vk}^{*} \mathrm{MYC}$ cell challenge. At this time point, a very low percentage of $\mathrm{MM}$ cells $(<1 \%)$ was detectable in the BM, and the tumor had not yet spread to the spleen (Supplemental Figure 5, A and B). To determine whether anti-CD137 mAb treatment could be delayed to treat advanced disease stages, MM-challenged WT mice were given a 2-week anti-CD137 mAb treatment starting at week 1, 2, 3, or 
A

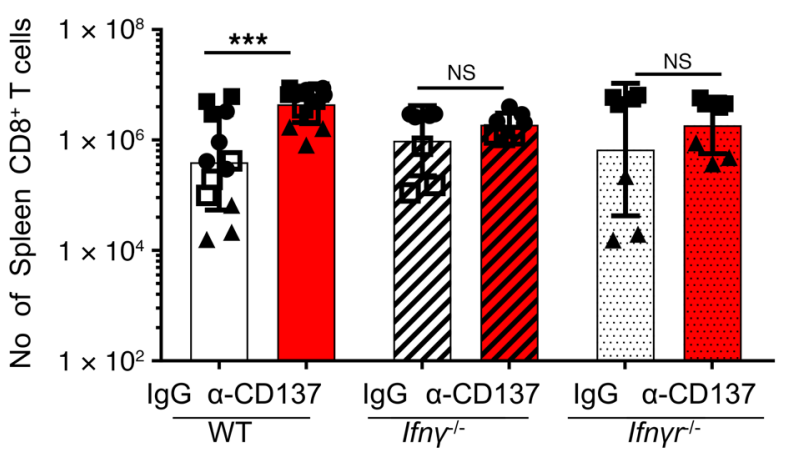

B

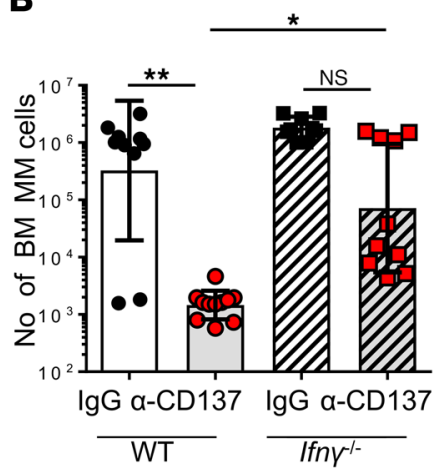

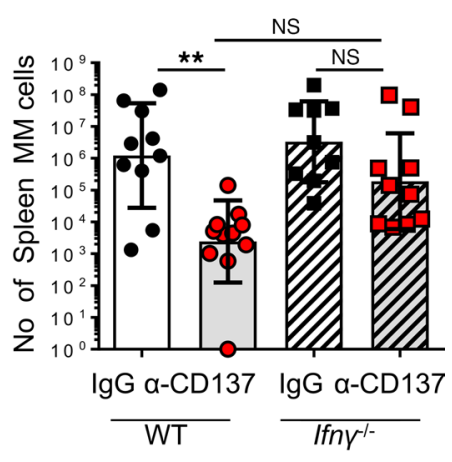
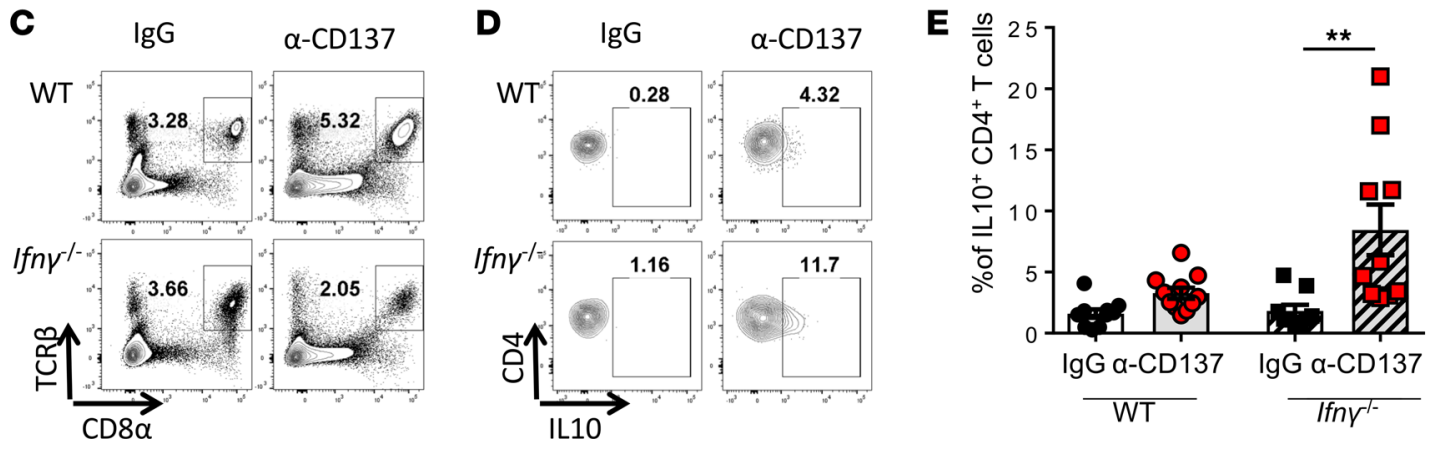

Figure 4. IFN- $\gamma$ signaling is required for optimal efficacy of anti-CD137 mAb therapy. (A) Naive WT, Ifn $\gamma^{-1-}$, and Ifn $\gamma r^{-1-}$ mice received a 2-week anti-CD137 $\mathrm{mAb}$ treatment, and $\mathrm{CD} 8^{+} \mathrm{T}$ cell numbers in the spleen were determined by flow cytometry. Graphs show geometric mean $\pm \mathrm{SD}$ of 4 pooled experiments (each with 3-4 mice per group). Data acquired within the same experiment are represented with similar symbols. (B-E) WT and Ifn $\gamma^{-1-}$ were challenged with Vk* MYC cells, and 2 weeks later, mice received a 2-week anti-CD137 mAb treatment. At week 5 after Vk* MYC cell challenge, numbers of BM (B, left) and spleen (B, right) MM cells, as well as (C) percentages of CD8 ${ }^{+}$T cells within BM lymphocytes were analyzed by flow cytometry. (D and E) Total BM cells were cultured with PMA-ionomycin for 2 hours, and IL-10 production by $\mathrm{CD}^{+}{ }^{+} \mathrm{T}$ cells was determined by intracellular staining. Graphs show (B) geometric mean \pm SD or $(\mathbf{E})$ mean \pm SEM of 1 experiment with $n=9-11$ mice per group. Data were analyzed with (A) a Mann-Whitney $U$ test or (B and $\mathbf{E})$ a Kruskal-Wallis test followed by Dunn's multiple-comparisons post hoc test. ${ }^{*} P<0.05,{ }^{* *} P<0.01,{ }^{* *} P<0.001$.

4 after $\mathrm{Vk} * \mathrm{MYC}$ cell injection (Supplemental Figure 5C). Tumor burden and serum M-protein level analyses indicated that anti-CD137 mAb treatment lost efficacy when delayed more than 3 weeks after $\mathrm{Vk}^{*} \mathrm{MYC}$ cell injection (Figure 5, A and B).

We hypothesized that MM-induced immunosuppression might contribute to the loss of anti$\mathrm{CD} 137 \mathrm{mAb}$ efficacy. To gain more insight into the course of natural immune responses to MM, we analyzed IFN- $\gamma$ production by $\mathrm{NK}$ and $\mathrm{T}$ cells in the BM of MM-bearing mice. Interestingly, in mice with low-tumor burden $\left(<4.8 \times 10^{5} \mathrm{MM}\right.$ cells), we observed a positive correlation between percentages of IFN- $\gamma$-producing $\mathrm{CD} 8^{+} \mathrm{T}$ cells and tumor burden in the $\mathrm{BM}$, whereas this correlation became negative in mice with higher tumor burden $\left(>4.8 \times 10^{5} \mathrm{MM}\right.$ cells; Figure $\left.5 \mathrm{C}\right)$. By contrast, no correlation was found between the percentages of IFN- $\gamma$-producing NK or CD4 ${ }^{+} \mathrm{T}$ cells and tumor burden in the BM (Supplemental Figure 5D). These data indicate that the developing tumor may trigger an initial $\mathrm{CD} 8^{+} \mathrm{T}$ cell response, but this response is then suppressed as the tumor grows. Moreover, percentages of $\mathrm{CD}^{+}$and $\mathrm{CD}^{+} \mathrm{T}$ cells producing the immunosuppressive cytokine IL-10 positively correlated with tumor burden in the BM (Figure 5D), thereby supporting the idea of progressive immunosuppression. These data suggest that the establishment of a suppressive microenvironment might contribute to the loss of efficacy of anti-CD137 mAbs against MM.

High MM burden does not prevent $T$ cells from responding to CD137 stimulation. To determine whether MM-induced immunosuppression hampers immune cell ability to respond to CD137 stimulation, we analyzed NK and T cell responses to a single injection of anti-CD137 mAbs given at either week 2 or week 4 after $\mathrm{Vk}{ }^{*} \mathrm{MYC}$ cell challenge. These 2 time points were chosen because very good therapeutic efficacy of anti-CD137 mAbs was obtained at week 2 and protection was lost at week 4 (Figure 5, A and B). Intriguingly, while NK cell numbers significantly dropped in response to week 2 anti-CD137 
A

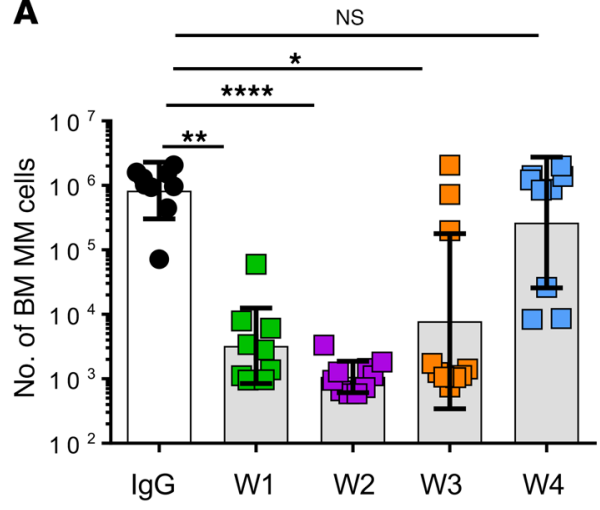

C

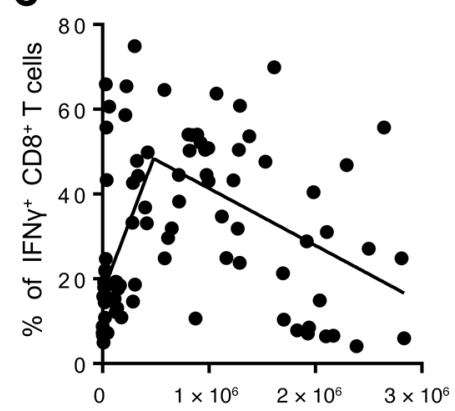

No of BM MM cells

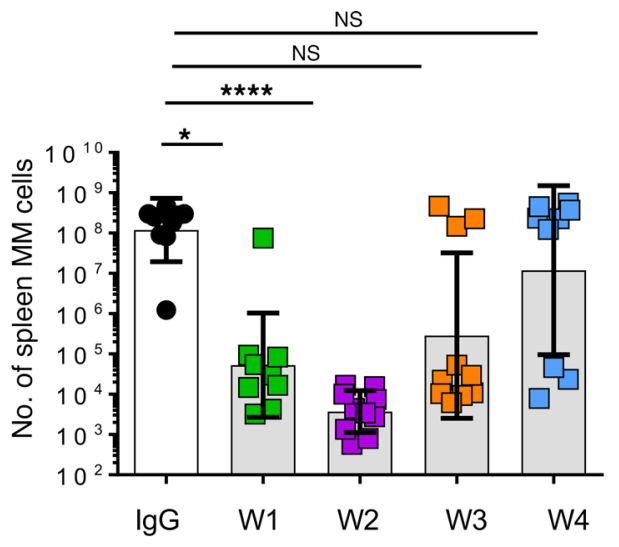

D

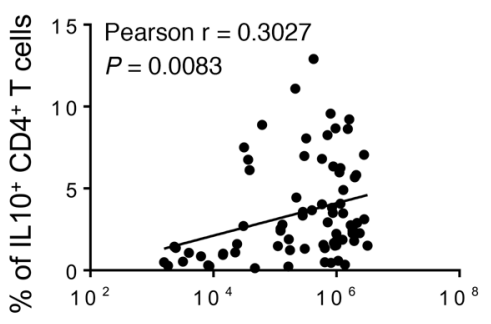

No of BM MM cells
B

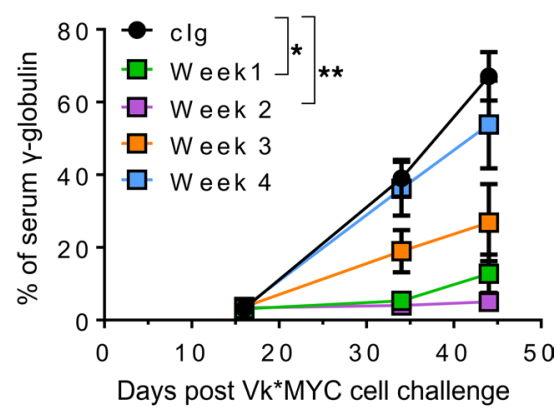

Figure 5. MM growth is associated with progressive immunosuppression and loss of anti-CD137 mAb treatment efficacy. (A and B) WT mice were challenged with Vk* MYC cells, and mice received a 2-week anti-CD137 mAb treatment starting at week 1, 2, 3, or 4 (W1, W2, W3, or W4) after Vk* MYC cell challenge (see Supplemental Figure 5C). (A) Tumor burden in the BM (left) and the spleen (right) was analyzed by flow cytometry at week 6 after V ${ }^{*} M Y C$ cell challenge. (B) Monoclonal gammopathy was analyzed over time by serum electrophoresis. Graphs display (A) geometric mean \pm SD or (B) mean \pm SEM of 1 experiment with $n=9-10$ mice per group. c, control. Data were analyzed with a Kruskal-Wallis test followed by Dunn's multiple-comparisons post hoc test performed on week-6 values. ${ }^{*} P<0.05,{ }^{* *} P<0.01$, ${ }^{* * *} P<0.0001$. (C and D) WT mice were challenged with Vk* MYC cells, and $3-6$ weeks later, BM cells were collected and cultured with PMA-ionomycin for 2 hours. (C) IFN- $\gamma$ production by CD8 ${ }^{+} \mathrm{T}$ cells and (D) IL-10 production by CD4+ and CD8 ${ }^{+} \mathrm{T}$ cells were measured by intracellular staining. Data were pooled from $n=9-10$ independent experiments with a total of $n=76-91$ mice that had either been left untreated or received control treatment (PBS or IgG). (C) Data were analyzed with the GraphPad Prism software using unconstrained segmental linear regression; $P<0.0001 ; X 0=479425$. (D) Data were analyzed with a Pearson's correlation test.

$\mathrm{mAb}$ injection, this decrease was much less pronounced at week 4 after $\mathrm{Vk} * \mathrm{MYC}$ cell challenge (Supplemental Figure 6, A and B). Importantly, anti-CD137 mAbs induced T cell proliferation and IFN- $\gamma$ production when given at either week 2 or week 4 after $\mathrm{Vk} * \mathrm{MYC}$ cell challenge (Figure $6, \mathrm{~A}$ and $\mathrm{B}$, and Supplemental Figure 6, C and D). Moreover, there was no correlation between percentages of IFN- $\gamma$ producing $\mathrm{CD}^{+}$or $\mathrm{CD} 8^{+} \mathrm{T}$ cells and tumor burden in mice that had received a 2-week anti-CD137 $\mathrm{mAb}$ treatment (Supplemental Figure 6E). Still, we observed a positive correlation between tumor burden and percentages of IL-10-producing $\mathrm{CD} 4^{+}$but not $\mathrm{CD} 8^{+} \mathrm{T}$ cells in these mice (Supplemental Figure $6 \mathrm{~F}$ ). Of note, most of IL-10-producing $\mathrm{CD}^{+} \mathrm{T}$ cells were also positive for IFN- $\gamma$ (Supplemental Figure $6, \mathrm{G}$ and $\mathrm{H})$. Together, these data indicate that $\mathrm{T}$ cell exhaustion is unlikely to be the reason for the lack of treatment efficacy; in high tumor burden-bearing mice, $\mathrm{CD} 4^{+}$and $\mathrm{CD} 8^{+} \mathrm{T}$ cells were still able to respond to $\mathrm{CD} 137$ stimulation by proliferating vigorously and by producing IFN- $\gamma$.

Reduced numbers of $C D 8^{+} T$ cells in association with high tumor burden might contribute to the lack of efficacy of delayed anti-CD137 $\mathrm{mAb}$ treatment. Even though equivalent $\mathrm{CD} 8^{+} \mathrm{T}$ cell proliferation was observed in response to week 2 or week 4 anti-CD137 mAb injection, we noticed that the numbers of BM CD8 ${ }^{+} \mathrm{T}$ cells obtained after CD137 stimulation were lower when this injection was given at week 4 (Figure 6C). In the BM of untreated mice, $\mathrm{CD} 8^{+} \mathrm{T}$ cell numbers dropped drastically when the tumor burden reached $10^{6}$ malignant plasma cells per femur (Figure 6D). Thus, in mice with high tumor burden, low numbers of $\mathrm{BM} \mathrm{CD} 8^{+} \mathrm{T}$ cells prior to anti-CD137 $\mathrm{mAb}$ therapy resulted in low numbers of $\mathrm{CD} 8^{+} \mathrm{T}$ cells after therapy, in spite of $\mathrm{CD} 137$-induced $\mathrm{CD} 8^{+} \mathrm{T}$ cell proliferation. Of note, the fold increase in $\mathrm{CD} 8^{+} \mathrm{T}$ cell numbers induced by $\mathrm{CD} 137 \mathrm{stimu}-$ 

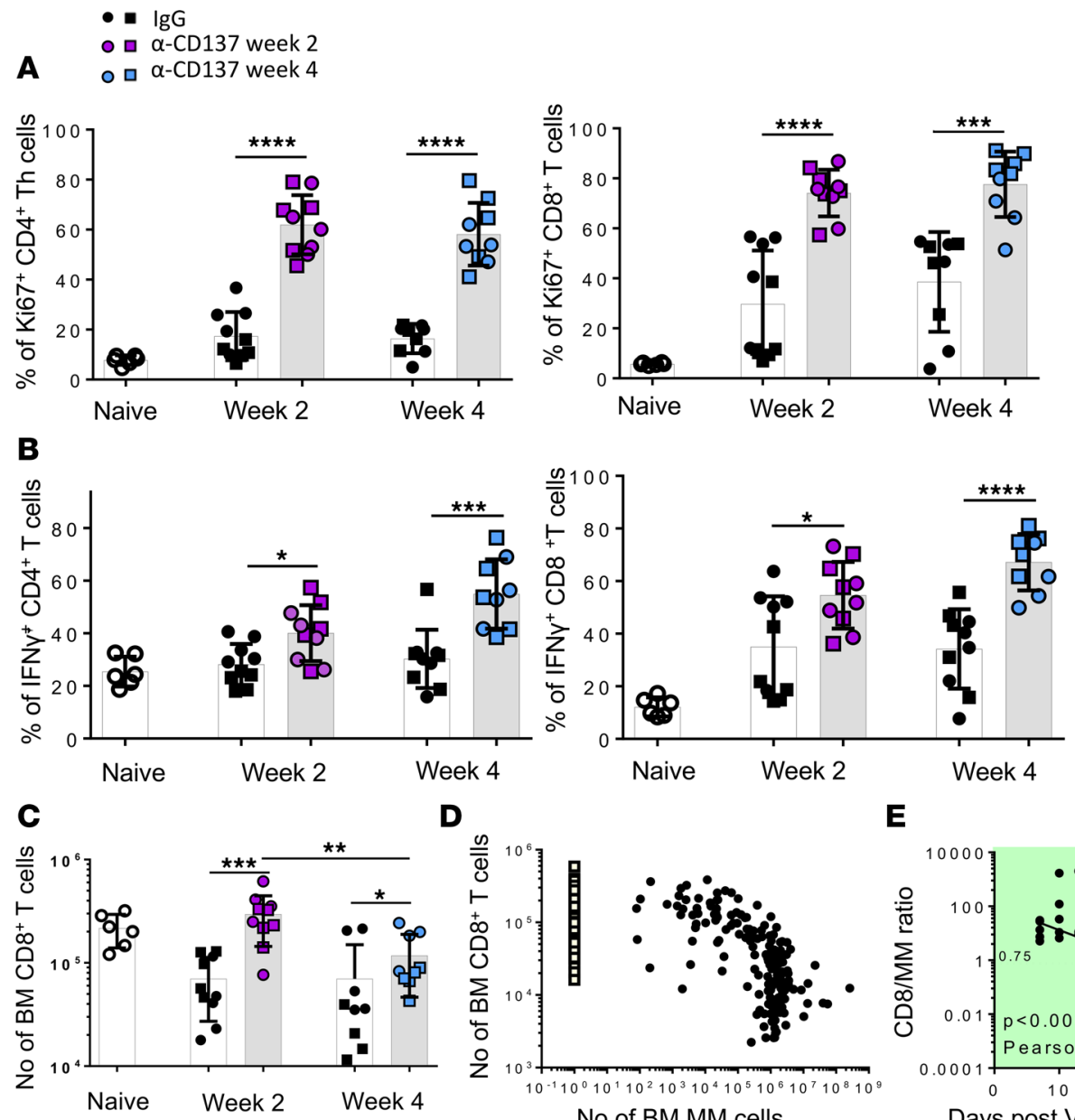

D

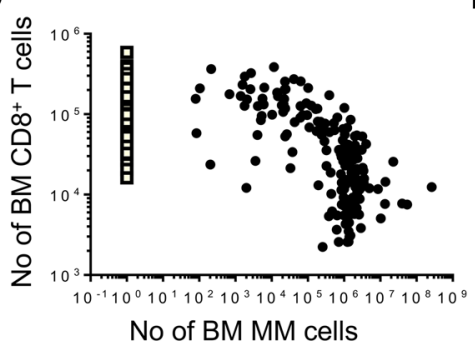

E

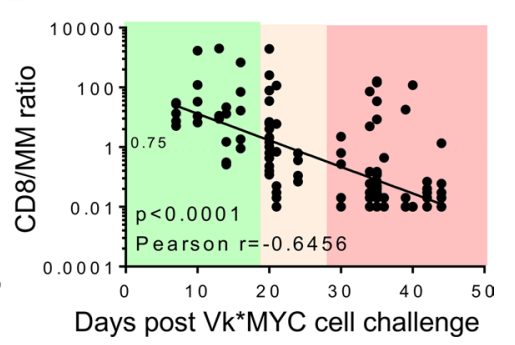

Figure 6. In mice with high MM burden, T cells are responsive to CD137 stimulation, but delayed anti-CD137 mAb treatment fails to expand large numbers of CD8 ${ }^{+}$T cells. (A-C) WT mice received a single injection of anti-CD137 mAbs at week 2 or 4 after $\mathrm{Vk}^{*} \mathrm{MYC}$ cell challenge. T cell responses in the BM were analyzed 1 week later. Naive mice were used as control. (A) Proliferation of CD4+ Th (FoxP3-) and CD8 ${ }^{+}$T cells was assessed by intracellular Ki-67 staining. (B) IFN- $\gamma$ production by $C D 4^{+}$and $C D 8^{+} T$ cells was assessed by intracellular staining. (C) $C D 8^{+} T$ cell numbers in the BM were determined by flow cytometry. (D and E) WT mice were challenged with Vk*MYC cells (filled circles), and 1-6 weeks later, numbers of CD8 ${ }^{+} T$ and MM cells in the BM were analyzed by flow cytometry. (D) CD8 ${ }^{+} \mathrm{T}$ cells in the BM of naive mice were analyzed as control (open squares) and were assigned the value of $1 \mathrm{MM}$ cell for plotting on the log axis. (E) The ratio between CD8 ${ }^{+} \mathrm{T}$ cells and tumor cells (CD8/MM ratio) was determined by flow cytometry at different time points. The color rectangles highlight data at time points when anti-CD137 mAb treatment generally decreased tumor growth in most of the mice (green), decreased tumor growth in only some mice (orange), or had no effect on tumor growth in most of the mice (red). Data were pooled from (A-C) $n=2$ independent experiments, each with $n=3-5$ mice per group, $(\mathbf{D}$ and $\mathbf{E}) n=16$ independent experiments with $n=60$ naive and $n=171 \mathrm{MM}$-bearing mice. Data were analyzed with $(\mathbf{A}-\mathbf{C})$ a Mann-Whitney $U$ test or (E) Pearson's correlation test; ${ }^{*} P<0.05,{ }^{* *} P<0.01,{ }^{* *} P<0.001,{ }^{* * *} P<0.0001$.

lation at week 2 was greater than the one at week 4 (increased 4.2 and 1.5 times, respectively), indicating that increased $\mathrm{CD}^{+} \mathrm{T}$ cell death might occur at week 4 . Furthermore, the CD8/MM ratio decreased with time after MM injection: before week 3 after MM injection, most of the mice had a CD8/MM ratio greater than 1 , whereas after week 4 this ratio dropped below 1 (Figure 6E). These data support the idea that an insufficient $\mathrm{CD} 8 / \mathrm{MM}$ ratio contributes to the lack of efficacy of delayed anti-CD137 $\mathrm{mAb}$ treatment.

Serum $M$-protein levels before treatment predict the efficacy of anti-CD137 mAbs. We hypothesized that tumor burden prior to treatment may be a predictive factor of anti-CD137 mAb treatment efficacy. To test this hypothesis, we divided mice into responders and nonresponders (Supplemental Figure 7A) and performed a logistic regression of response versus pretreatment M-protein levels (Figure 7A and Supplemental Figure 7B). This logistic model correctly classified 15 of $17(88 \%)$ responders as responders and 8 of $10(80 \%)$ nonresponders as nonresponders. This model indicates that mice displaying pretreatment M-protein levels less than $7.3 \%$ are likely to respond to anti-CD137 mAb treatment (predicted efficacy of $95 \%$ ), whereas treatment would fail in mice with initial M-proteins levels greater than $29.4 \%$ (predicted failure rate of $95 \%$ ). Moreover, a partition tree performed on the same data set and using a cutoff value of $10.2 \%$ for pre- 
A

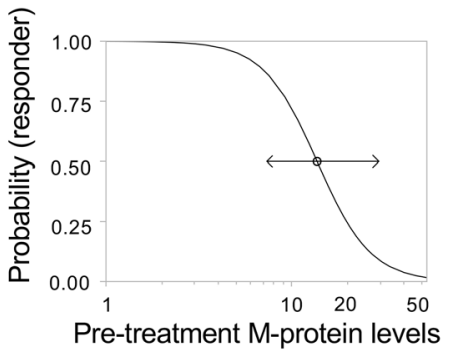

B

\begin{tabular}{|l|c|c|}
\cline { 2 - 3 } \multicolumn{1}{c|}{} & $\begin{array}{c}\text { Non- } \\
\text { responder }\end{array}$ & Responder \\
\hline $\begin{array}{l}\text { Identified as } \\
\text { non-responder } \\
\text { Identified as } \\
\text { responder }\end{array}$ & 8 & 2 \\
\hline Total & 2 & 15 \\
\hline
\end{tabular}

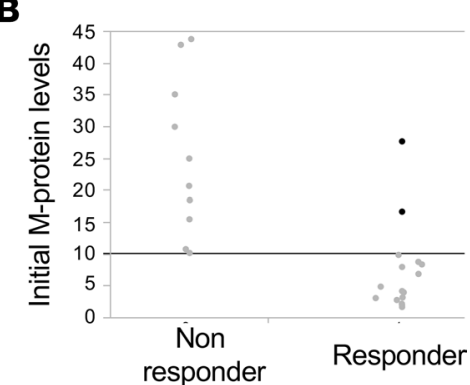

Figure 7. Initial MM burden determines treatment efficacy. (A and B) WT mice were challenged with Vk*MYC cells, and 2-4 weeks later, serum M-protein levels were measured before the mice were given a 2-week anti-CD137 mAb treatment. Mice were categorized as responders if their serum M-protein levels after treatment were less than $30 \%$. Data from 3 independent experiments with a total of $n=30$ mice were analyzed. (A) Logistic fit (left) and corresponding confusion matrix (right) of the probability of being a nonresponder versus pretreatment $M$-protein levels (likelihood ratio $X_{1}^{2}=19.0, P<0.0001$ ). According to this analysis, mice with pretreatment M-protein levels of $13.61 \%(95 \% \mathrm{Cl} 7.34,29.37)$ have a $50 \%$ chance of responding to the treatment. (B) Partition tree classifying mice with pretreatment M-protein levels $<10.2 \%$ as responders and others as nonresponders.

treatment M-protein levels correctly identified 15 of 17 responders and all 10 nonresponders (Figure 7B). Overall, these analyses indicate that treatment efficacy depends on initial tumor burden.

In silico modeling of $C D 8^{+} T$ cell-MM cell interactions and their impact on treatment efficacy. To further understand the interactions between $\mathrm{CD} 8^{+} \mathrm{T}$ cells and $\mathrm{MM}$ cells in the $\mathrm{BM}$, we developed a mathematical model by adapting the model recently proposed by Doban et al. (25) to fit our data (see Supplemental Methods). This model utilizes delay differential equations to describe the interactions between 4 populations: MM cells (M), naive $\mathrm{CD}^{+} \mathrm{T}$ cells $(\mathrm{Z})$, activated $\mathrm{CD} 8^{+} \mathrm{T}$ cells $(\mathrm{A})$, and exhausted $\mathrm{CD} 8^{+} \mathrm{T}$ cells $(\mathrm{E})$ (Supplemental Figure 8A). The 4 equations that determine these interactions are shown in Supplemental Methods and are described as follows: (i) rate of change of $\mathrm{MM}$ cell population $=\mathrm{MM}$ cell growth $-\mathrm{MM}$ cell killing by activated $\mathrm{CD} 8^{+} \mathrm{T}$ cells; (ii) rate of change of activated $\mathrm{CD} 8^{+} \mathrm{T}$ cell population $=$ proliferation of activated $\mathrm{CD} 8^{+} \mathrm{T}$ cells + steady-state conversion of naive $\mathrm{CD}^{+} \mathrm{T}$ cells into activated $\mathrm{CD} 8^{+} \mathrm{T}$ cells $+\mathrm{MM}$-induced conversion of naive $\mathrm{CD} 8^{+} \mathrm{T}$ cells into activated $\mathrm{CD}^{+} \mathrm{T}\left(^{*}\right)+$ anti-CD137 $\mathrm{mAb}$ treatment-induced conversion of naive $\mathrm{CD} 8^{+} \mathrm{T}$ cells into activated $\mathrm{CD} 8^{+}$ $\mathrm{T}-$ contraction of activated $\mathrm{CD} 8^{+} \mathrm{T}$ cells $-\mathrm{MM}$-induced conversion of activated $\mathrm{CD} 8^{+} \mathrm{T}$ cells into exhausted $\mathrm{CD}^{+} \mathrm{T}$ cells; (iii) rate of change of naive $\mathrm{CD} 8^{+} \mathrm{T}$ cell population $=$ proliferation/arrival of naive $\mathrm{CD} 8^{+} \mathrm{T}$ cells - steady-state conversion of naive $\mathrm{CD}^{+} \mathrm{T}$ cells into activated $\mathrm{CD} 8^{+} \mathrm{T}$ cells $-\mathrm{MM}$-induced conversion of naive $\mathrm{CD}^{+} \mathrm{T}$ cells into activated $\mathrm{CD} 8^{+} \mathrm{T}\left(^{*}\right)$ - anti-CD137 mAb treatment-induced conversion of naive $\mathrm{CD} 8^{+} \mathrm{T}$ cells into activated $\mathrm{CD} 8^{+} \mathrm{T}-$ suppression of naive $\mathrm{CD} 8^{+} \mathrm{T}$ cell by MM cells; (iv) rate change of exhausted $\mathrm{CD} 8^{+} \mathrm{T}$ cell population $=$ MM-induced conversion of activated $\mathrm{CD}^{+} \mathrm{T}$ cells into exhausted $\mathrm{CD} 8^{+} \mathrm{T}$ cells - death of exhausted CD8 ${ }^{+} \mathrm{T}$ cells. $\left(^{*}\right)$ indicates that when the tumor burden is decreasing, there is no MM-induced conversion of naive $\mathrm{CD}^{+} \mathrm{T}$ cells into activated $\mathrm{CD} 8^{+} \mathrm{T}$ cells, and thus this term is set to zero.

Interactions between these populations are regulated by various parameters, such as $\mathrm{MM}$ and $\mathrm{CD} 8^{+}$ $\mathrm{T}$ cell growth rates, conversion rates of naive into activated $\mathrm{CD} 8^{+} \mathrm{T}$ cells and of activated into exhausted $\mathrm{CD}^{+} \mathrm{T}$ cells, killing capacity of activated $\mathrm{CD} 8^{+} \mathrm{T}$ cells, and MM suppressive effect (see Supplemental Methods). We first selected parameters so that the 4 population dynamics reflected the data we obtained in untreated mice. In these settings, MM tumors grew very slowly until day 21, and then cell numbers increased rapidly, reaching a plateau around day 60 (Figure 8A). In parallel, numbers of naive CD8 ${ }^{+}$ $\mathrm{T}$ cells decreased due to their conversion into activated $\mathrm{CD} 8^{+} \mathrm{T}$ cells and the suppressive effect of the tumor. The activated $\mathrm{CD} 8^{+} \mathrm{T}$ cell population increased up to day 12 , but as MM tumors grew, these cells were suppressed and converted into exhausted $\mathrm{CD} 8^{+} \mathrm{T}$ cells that finally died, leading to a profound decrease in total $\mathrm{CD} 8^{+} \mathrm{T}$ cell numbers. We then defined the best-fitting parameters for anti-CD137 $\mathrm{mAb}$ treatment under the assumption that this therapy would induce further conversion of naive $\mathrm{CD}^{+} \mathrm{T}$ cells into activated $\mathrm{CD} 8^{+} \mathrm{T}$ cells and increase the growth, survival, and killing capacity of activated $\mathrm{CD} 8^{+}$ T cells (see Supplemental Methods and Supplemental Figure 8B). With these parameters, anti-CD137 $\mathrm{mAb}$ treatment failed to eradicate the tumor if given on day 25 or later (Figure $8, \mathrm{~B}$ and $\mathrm{C}$ ), when the $\mathrm{CD} 8 / \mathrm{MM}$ ratio was 0.75 . These values are consistent with our data in the $\mathrm{Vk}{ }^{*} \mathrm{MYC} M \mathrm{MM}$ model (Figure $5, \mathrm{~A}$ and $\mathrm{B}$, and Figure $6 \mathrm{E}$ ). Interestingly, in these conditions, the ratio of activated $\mathrm{CD} 8^{+} \mathrm{T}$ cells to $\mathrm{MM}$ cells on day 25 was 0.13 , indicating that more than 1 effector cell is needed to kill $10 \mathrm{MM}$ cells. We then 


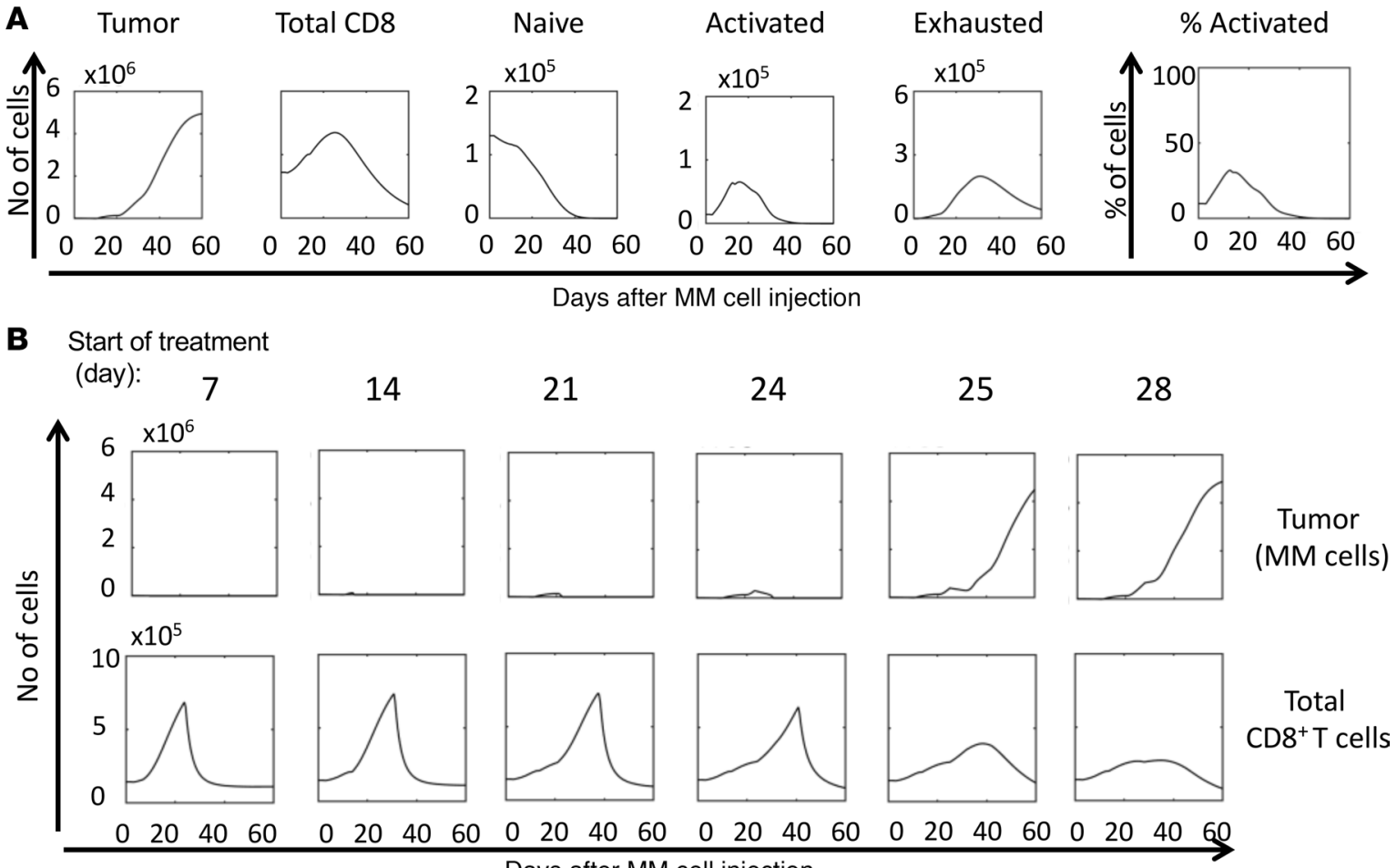

Days after MM cell injection

C Start of treatment

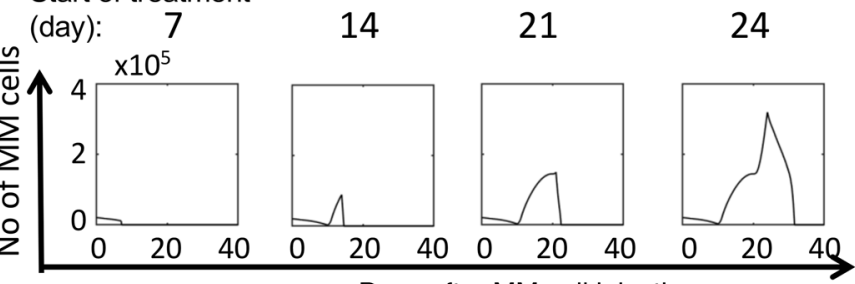

Days after MM cell injection

Figure 8. Modeling interactions between CD8 ${ }^{+} \mathrm{T}$ cells and MM cells in the context of anti-CD137 mAb treatment. Dynamic interactions between MM cells and CD8 ${ }^{+}$T cells were modeled in silico. (A) Numbers of MM cells and naive, activated, and exhausted CD8+ T cells over time using optimized parameters to fit the experimental data in untreated mice. (B and C) Effect of a 2-week anti-CD137 mAb treatment started at different time points between days 7 and 28 after MM injection. (B) Graphs within a column represent the numbers of MM cells and total CD8 ${ }^{+} T$ cells over time when treatment was started on a given day after MM injection (indicated at the top of each column). (C) Scale from graphs in B was adjusted to visualize the evolution of MM cell numbers when treatment was efficient.

modified the number of tumor cells reaching the $\mathrm{BM}$ and their growth rate to mimic differences between batches of Vk* MYC cells (Table 1). As expected, if more tumor cells reached the BM or if their growth rate was increased, anti-CD137 mAb treatment lost efficacy earlier. Loss of efficacy was also observed earlier when the suppressive effect of $\mathrm{MM}$ cells on activated $\mathrm{CD} 8^{+} \mathrm{T}$ cells was increased. By contrast, $\mathrm{MM}$ cells' suppressive effect on naive $\mathrm{CD} 8^{+} \mathrm{T}$ cells only modestly modulated treatment efficacy. Finally, we tested different killing capacities of $\mathrm{CD}^{+} \mathrm{T}$ cells. When anti-CD137 mAb treatment had no effect on activated $\mathrm{CD} 8^{+} \mathrm{T}$ cell killing capacity (i.e., it only induced the conversion of naive into activated $\mathrm{CD} 8^{+} \mathrm{T}$ cells, increased the growth and survival of activated $\mathrm{CD} 8^{+} \mathrm{T}$ cells, and thus resulted in increased numbers of activated $\mathrm{CD} 8^{+} \mathrm{T}$ cells without enhanced killing capacity), this 2-week treatment failed to eradicate the tumor when given beyond day 8 . Moreover, for the treatment to be efficient beyond 4 weeks after myeloma injection, the killing capacity of $\mathrm{CD} 8^{+} \mathrm{T}$ cells had to be 10 times higher than the value set in untreated conditions. Overall, this model captures the complexity of the interactions between $\mathrm{CD} 8^{+}$ $\mathrm{T}$ cells and MM cells and indicates that anti-CD137 mAb treatment efficacy is dependent on multiple parameters, including CD8/MM ratio, MM cell growth rate, MM cell suppressive activity, and ability of the treatment to stimulate efficient $\mathrm{CD} 8^{+} \mathrm{T}$ cell-mediated killing. Importantly, we show that even minor modification of one of these parameters can have a dramatic impact on treatment outcome. 
Table 1. Influence of different parameters on the ability of anti-CD137 mAb treatment to eliminate MM cells

\begin{tabular}{|c|c|c|c|c|c|c|}
\hline $\begin{array}{l}\text { Value of the } \\
\text { modified parameter }\end{array}$ & $\begin{array}{c}\text { Time }\left(t_{\text {lim }}\right) \text { when } \\
\text { the treatment no } \\
\text { longer eradicates the } \\
\text { tumor (d) }\end{array}$ & MM cells at $t_{\text {lim }}$ (no.) & $\begin{array}{l}\text { Total CD8 }{ }^{+} T \text { cells } \\
\text { at } t_{\text {lim }} \text { (no.) }\end{array}$ & $\begin{array}{l}\text { Activated CD8 } \\
\text { T cells at } t_{\text {lim }} \text { (no.) }\end{array}$ & $\begin{array}{c}\text { Ratio total } \\
\text { CD8 }+ \text { MM cells at } t_{\text {lim }}\end{array}$ & $\begin{array}{c}\text { Ratio activated } \\
\text { CD8 }{ }^{+} / M M \text { cells at } t_{\text {lim }}\end{array}$ \\
\hline 19295 & 34 & 403,717 & 284,635 & 43,757 & 0.71 & 0.11 \\
\hline 20000 & 26 & 389,569 & 269,031 & 46,704 & 0.69 & 0.12 \\
\hline 23000 & 23 & 312,781 & 267,544 & 45,226 & 0.86 & 0.14 \\
\hline 24000 & 23 & 296,769 & 266,020 & 44,412 & 0.90 & 0.15 \\
\hline 25000 & 22 & 278,684 & 264,195 & 43,834 & 0.95 & 0.16 \\
\hline 50000 & 18 & 387,572 & 217,914 & 37,032 & 0.56 & 0.10 \\
\hline 100000 & 14 & 440,246 & 176,642 & 37,441 & 0.40 & 0.09 \\
\hline 500000 & 5 & 494,804 & 128,816 & 11,608 & 0.26 & 0.02 \\
\hline 0.2 & 35 & 390,557 & 318,888 & 33,747 & 0.82 & 0.09 \\
\hline 0.25 & 30 & 446,560 & 295,064 & 38,984 & 0.66 & 0.09 \\
\hline 0.3 & 27 & 427,168 & 281,024 & 43,924 & 0.66 & 0.10 \\
\hline 0.35 & 25 & 360,933 & 268,938 & 46,223 & 0.75 & 0.13 \\
\hline 0.5 & 20 & 207,649 & 244,304 & 45,212 & 1.18 & 0.22 \\
\hline 1 & 17 & 364,732 & 220,417 & 41,604 & 0.60 & 0.11 \\
\hline 2 & 15 & 502,561 & 207,402 & 47,524 & 0.41 & 0.09 \\
\hline 5 & 11 & 341,400 & 191,310 & 61,290 & 0.56 & 0.18 \\
\hline \multicolumn{7}{|c|}{ Suppressive effect of MM cells on activated CD8 ${ }^{+} T$ cells $\left(\sigma_{A}\right)$; fitted value: 0.05} \\
\hline 0.03 & 30 & 708,163 & 335,116 & 71,671 & 0.47 & 0.10 \\
\hline 0.04 & 27 & 520,800 & 29,7450 & 58,145 & 0.57 & 0.11 \\
\hline \multicolumn{7}{|c|}{ Suppressive effect of MM cells on naive $\mathrm{CD}^{+} \mathrm{T}$ cells $\left(\sigma_{\mathrm{z}}\right)$; fitted value: 0.01} \\
\hline 0.001 & 25 & 411,226 & 329,734 & 46,078 & 0.80 & 0.11 \\
\hline 0.01 & 25 & 360,933 & 268,938 & 46,223 & 0.75 & 0.13 \\
\hline 0.1 & 24 & 294,140 & 188,722 & 45,112 & 0.64 & 0.15 \\
\hline 1 & 24 & 312,977 & 187,503 & 45,018 & 0.60 & 0.14 \\
\hline \multicolumn{7}{|c|}{ Killing capacity of activated CD8 ${ }^{+}$T cells during treatment $(\gamma)$; fitted value: 2.7} \\
\hline 0.08 & 8 & 9783 & 166,394 & 37342 & 17.01 & 3.82 \\
\hline 0.1 & 9 & 6340 & 175,319 & 44,253 & 27.65 & 6.98 \\
\hline 0.5 & 18 & 134,923 & 234,922 & 63,878 & 1.74 & 0.47 \\
\hline 1 & 20 & 144,561 & 250,373 & 57,532 & 1.73 & 0.40 \\
\hline 2 & 23 & 234,604 & 265,356 & 50,578 & 1.13 & 0.22 \\
\hline 3 & 25 & 405,878 & 269,182 & 44,063 & 0.66 & 0.11 \\
\hline 5 & 27 & 598,287 & 266,904 & 33,228 & 0.45 & 0.06 \\
\hline 8 & 29 & 750,472 & 260,476 & 24,300 & 0.35 & 0.03 \\
\hline 10 & 29 & 795,583 & 256,642 & 21,208 & 0.32 & 0.03 \\
\hline
\end{tabular}

Fitted values for each parameter were determined to best fit the experimental observations and were kept constant, as different values for each parameter were tested individually to determine their influence on the CD8+ T cell-MM cell dynamics within the system. Bold text indicates the fitted value for each parameter. 
A

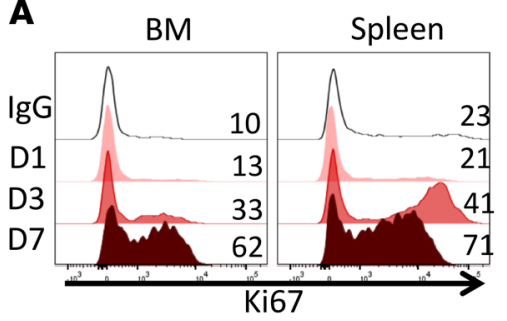

B

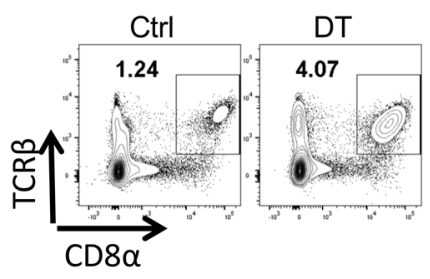

DT

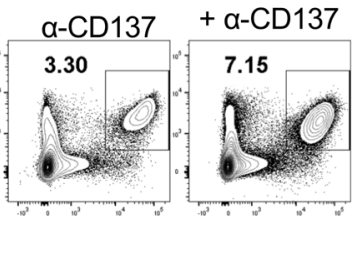

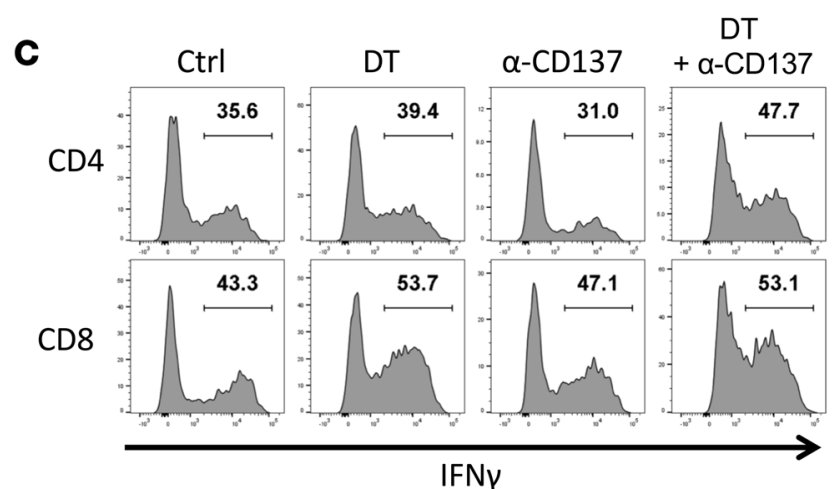

D

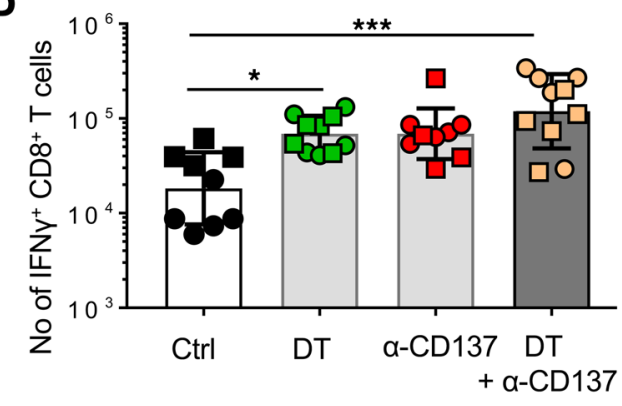

E

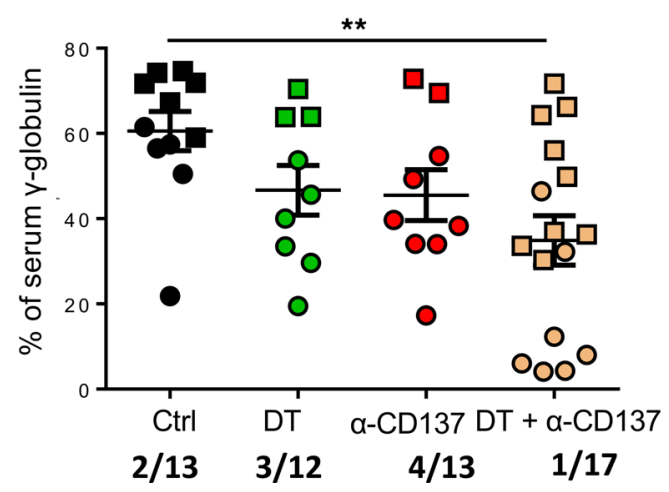

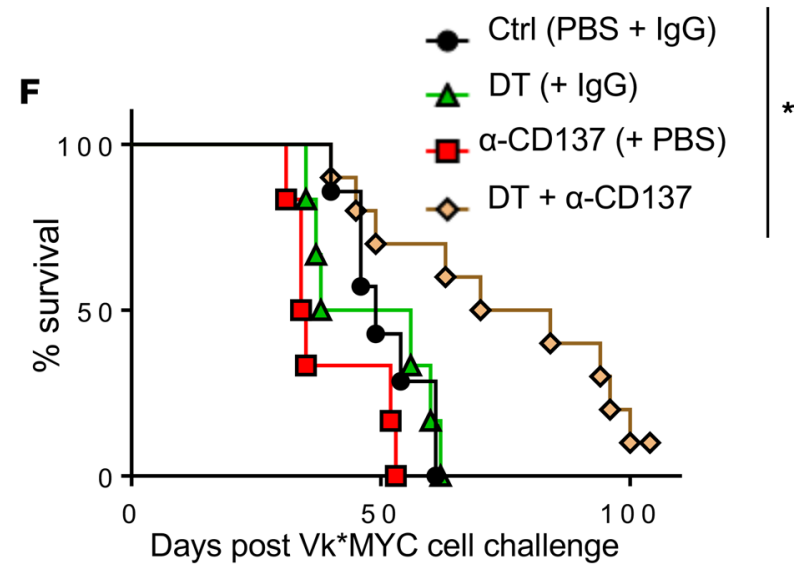

Figure 9. Treg depletion promotes the expansion of IFN- $\gamma$-producing CD8 ${ }^{+}$T cells in the BM and restores the efficacy of delayed anti-CD137 mAb treatment. (A) WT mice received a single anti-CD137 mAb injection on day 0, and FoxP3 ${ }^{+}$Treg proliferation was analyzed on days 1, 3, and 7. (B-D) FoxP3-DTR mice were challenged with $\mathrm{Vk}^{*}$ MYC cells on day 0 and were given $250 \mathrm{ng}$ DT (or PBS as control) on day 21 and a single injection of anti-CD137 mAbs (or control IgG) on day 22. BM T cells were analyzed by flow cytometry on day 28. (B) CD8 ${ }^{+} T$ cell percentages, gated on live CD45.2 $2^{+}$lymphocytes. (C) Percentages of IFN- $\gamma^{+} \mathrm{CD} 4^{+}$and $\mathrm{CD} 8^{+} \mathrm{T}$ cells. (D) Quantification of IFN- $\gamma^{+} \mathrm{CD} 8^{+} T$ cell numbers. (E and $\mathbf{F}$ ) FoxP3-DTR mice were challenged with $\mathrm{Vk}{ }^{*} \mathrm{MYC}$ cells on day 0. Mice received $250 \mathrm{ng}$ DT on days 24 and 29, together with a 2-week anti-CD137 mAb treatment from day 25. (E) At the end of the treatment, serum M-protein levels were determined by electrophoresis. Numbers indicate the number of mice that were sacrificed because they displayed severe MM symptoms (as explained in the Methods). (F) Survival was followed over time. Data are (A-C) representative or shown as (D) geometric mean \pm SD or (E) mean \pm SEM of 2 experiments, each with $n=5-10$ mice per group. Symbol shapes identify data from independent experiments. (F) Kaplan-Meier plot; data are from 1 experiment with $n=6-10$ mice per group. Data were analyzed using ( $\mathbf{D}$ and $\mathbf{E}$ ) a Kruskal-Wallis test followed by a Dunn's multiple-comparisons post hoc test or $(\mathbf{H})$ a log-rank test; ${ }^{*} P<0.05,{ }^{* *} P<0.01,{ }^{* * *} P<0.001,{ }^{* * *} P<0.0001$.

Treg depletion increases BMCD8 $T$ cell numbers and restores the efficacy of delayed anti-CD137 mAb treatment. Our in silico analysis indicated that the suppressive effect of MM cells on $\mathrm{CD} 8^{+} \mathrm{T}$ cells influences the outcome of anti-CD137 mAb treatment. This suppressive effect can be either direct or indirect, through the induction of immunosuppressive cells such as Tregs. A recent study indicated that Tregs' immunosuppressive functions were increased in MM (26). To assess whether Treg-mediated suppression impairs anti-CD137 mAb treatment efficacy, we first analyzed Treg responses during the course of anti-CD137 mAb treatment. We found that a single injection of anti-CD137 mAbs induced strong Treg proliferation in both tumor-naive (Figure 9A) and MM-bearing mice (Supplemental Figure 9A). There was no difference in Treg numbers obtained following CD137 stimulation between week-2 and week-4 MM-bearing mice (Supplemental Figure 9B), suggesting that Treg responses to CD137 stimulation are similar at early- and late-disease stages. Next, we asked whether Tregs 
A

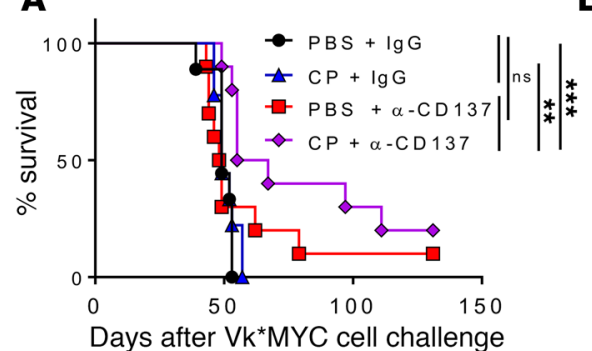

D $\quad 31 \%$

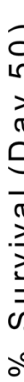

B

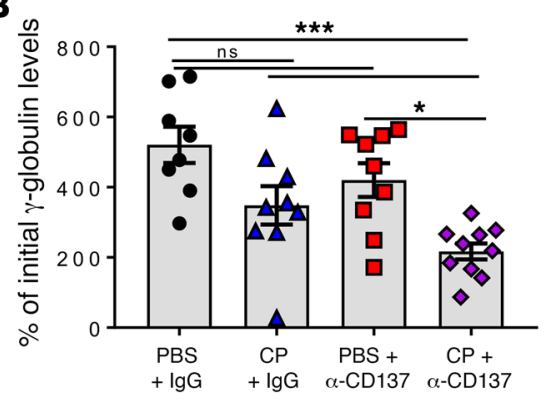

C

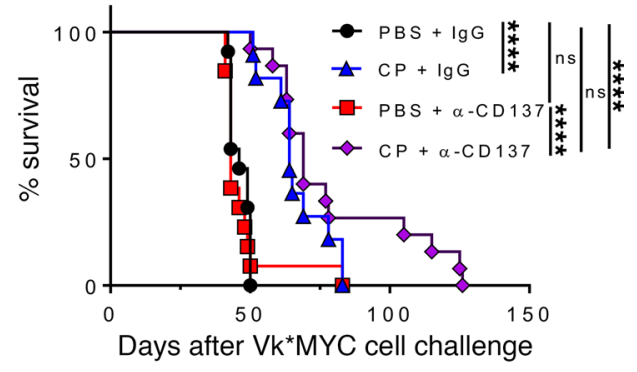

$81 \%$

$17 \%$

$97 \%$
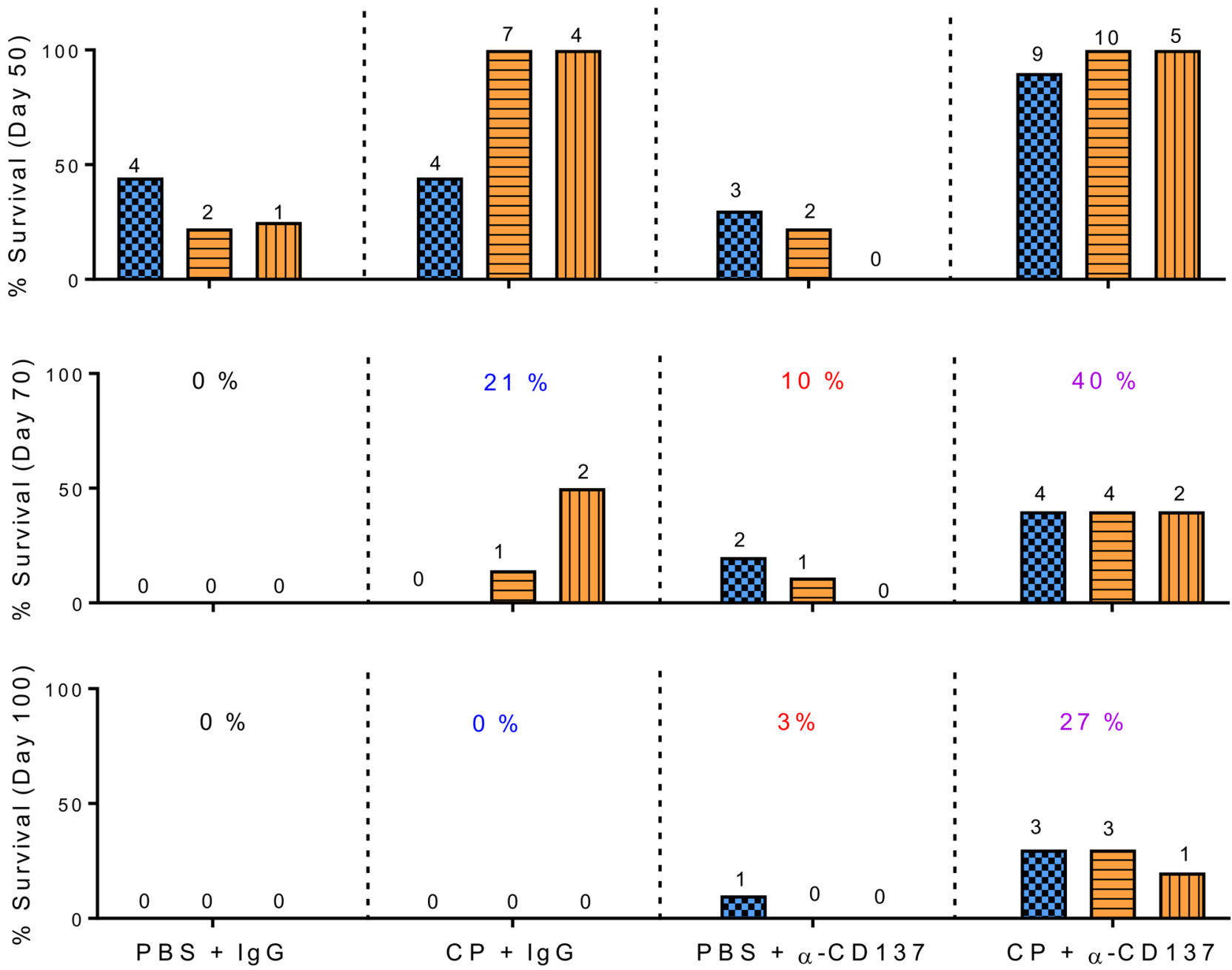

\section{Experiment 1 Experiment 2 Experiment 3}

Figure 10. Anti-CD137 mAb treatment prevents relapse after cyclophosphamide treatment and allows long-term survival. C57BL/6 WT mice were challenged with $\mathrm{Vk}^{*} \mathrm{MYC}$ cells on day 0 . Four weeks later, mice received a treatment consisting of 2 injections of cyclophosphamide (CP) followed by 2-week anti-CD137 mAb treatment (as detailed in Supplemental Figure 10C). (A and B) Mice were injected with $25 \mathrm{mg} / \mathrm{kg}$ CP on days 27 and 28. (A) Survival was monitored over time. (B) Serum electrophoresis was performed on day 26 (before treatment) and on day 41 ( 2 weeks after the treatment started). Variation in $\gamma$-globulin levels between these 2 time points is displayed as mean \pm SEM. Data are from 1 experiment with $n=8-10$ mice per group. (C) Mice were injected with $100 \mathrm{mg} / \mathrm{kg}$ CP on day 28 and 29. Kaplan-Meier plot; data were combined from 2 independent experiments with $n=11-15$ mice per group. (D) Data from $\mathbf{A}$ (experiment 1 ) and $\mathbf{C}$ (experiments 2 and 3 ) are shown as percentages of mice alive on days 50,70 , and 100 . Numbers at the top of each bar indicate the absolute number of mice alive at a given time point. The mean percentages of surviving mice within each group are indicated. Data were analyzed with a log-rank test $(\mathbf{A}$ and $\mathbf{C})$ or with a Kruskal-Wallis test $(\mathbf{B})$. ${ }^{*} P<0.05,{ }^{* *} P<$ $0.01,{ }^{* *} P<0.001,{ }^{* * *} P<0.0001$ 
A

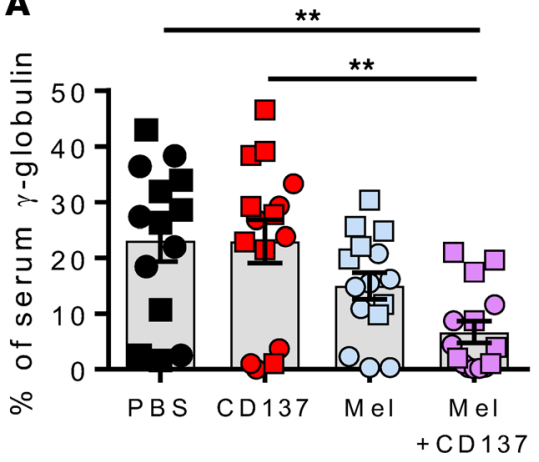

B

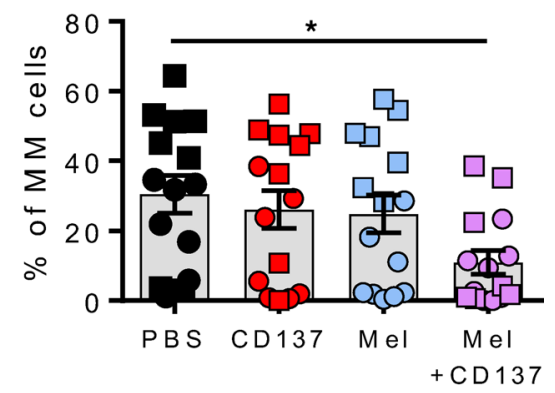

Figure 11. Sequential therapy with melphalan injections followed by anti-CD137 mAb treatment improves disease control. C57BL/ 6 WT mice were challenged with Vk* MYC cells on day 0 . On days 21 and 22, mice were injected i.p. with $4 \mathrm{mg} / \mathrm{kg}$ melphalan (Mel). Mice received a 2-week anti-CD137 mAb treatment starting on day 25. On day 45, (A) serum levels of $\gamma$-globulin (M-protein) were analyzed by electrophoresis, and (B) percentages of MM cells in the BM were determined by flow cytometry. Data are shown as mean \pm SEM of 2 experiments, each with 6-8 mice per group. Symbol shapes identify data from independent experiments. Data were analyzed with a Kruskal-Wallis test followed by Dunn's multiple-comparisons post hoc test. ${ }^{*} P<0.05,{ }^{* *} P<0.01$.

might impair CD137-mediated activation of T cells in MM-bearing mice. We took advantage of FoxP3-DTR mice, in which Tregs are depleted by the injection of diphtheria toxin (DT; ref. 27). At week 3 after Vk*MYC cell challenge, mice received a single DT injection followed by a single injection of anti-CD137 mAbs. We observed that DT injection alone increased CD8 ${ }^{+} \mathrm{T}$ cell numbers in the $\mathrm{BM}$ as well as IFN- $\gamma$ production by both $\mathrm{CD}^{+}$ and $\mathrm{CD} 8^{+} \mathrm{T}$ cells, and this was further enhanced when mice received a combination of DT and anti-CD137 mAbs (Figure 9, B-D, and Supplemental Figure 9C). To determine the impact of Treg depletion on treatment efficacy, we challenged FoxP3-DTR mice with $\mathrm{Vk}^{*} \mathrm{MYC}$ cells, and 3.5 weeks later, mice received a 2-week antiCD137 mAb treatment combined with DT injections. At week 6 after MM challenge, we observed a significant increase in $\mathrm{BM} \mathrm{CD}^{+} \mathrm{T}$ cell numbers in mice that received DT treatment alone or combined with anti-CD137 mAbs, but not in mice treated with single-agent anti-CD137 mAbs (Supplemental Figure 9D). We observed a nonsignificant trend toward decreased M-protein levels in mice treated with DT or anti-CD137 mAbs alone, but only the combination of Treg depletion and anti-CD137 mAbs significantly reduced monoclonal gammopathy and prolonged the survival of MM-challenged mice (Figure 9, E and F). These results indicate that Treg-induced immunosuppression limits the efficacy of anti-CD137 mAb treatment. Therefore, we tested whether alleviating immunosuppression through checkpoint blockade could restore the efficacy of delayed anti-CD137 mAb treatment. However, in our hands, neither anti-PD-1 nor anti-CTLA-4 mAbs improved the anti-MM effect of delayed anti-CD137 mAb treatment (Supplemental Figure 9, E and F). Taken as a whole, these data establish that efficient Treg depletion (but not PD-1 or CTLA-4 blockade) increases the effector T cell IFN- $\gamma$ response, expands BM CD8 ${ }^{+} \mathrm{T}$ cells, and improves the efficacy of anti-CD137 mAb therapy against MM.

Consolidation treatment with anti-CD137 mAbs following chemotherapy prolongs the survival of MM-bearing mice. We have established that tumor burden at the time of treatment is a determining factor for anti-CD137 mAb efficacy. Thus, we investigated whether combination with cytotoxic agents that would debulk the tumor could restore the efficacy of delayed anti-CD137 mAb treatment. At week 3 after Vk* MYC cell challenge, mice were given an anti-CD137 mAb treatment combined with low-dose cyclophosphamide $(20 \mathrm{mg} / \mathrm{kg}$; Supplemental Figure 10A). However, this combination did not show improved efficacy when compared with anti-CD137 mAb treatment alone. This result may be explained by the inability of low-dose cyclophosphamide to significantly reduce the tumor burden and by its immunosuppressive effects leading to reduced $\mathrm{CD}^{+} \mathrm{T}$ cell numbers (Supplemental Figure 10, A and B). Therefore, we next tested a sequential treatment approach. First, we tested whether anti-CD137 mAbs were effective when given after cyclophosphamide treatment. At week 3 after $\mathrm{Vk}^{*} \mathrm{MYC}$ cell challenge, 2 groups of mice were given 2 injections of $20 \mathrm{mg} / \mathrm{kg}$ cyclophosphamide, followed by a 2-week anti-CD137 mAb or IgG control treatment (Supplemental Figure 10C). Direct comparison of mice receiving cyclophosphamide only and mice receiving a sequential treatment of cyclophosphamide followed by anti-CD137 mAbs indicated that, when given after cyclophosphamide injections, delayed anti-CD137 mAb treatment led to increased numbers of BM CD8 ${ }^{+} \mathrm{T}$ cells, associ- 
ated with reduced tumor burden in the spleen and BM and reduced serum M-protein levels (Supplemental Figure 10, D-F). We then performed experiments with 4 groups of mice to include no treatment and antiCD137 mAb single treatment, in addition to cyclophosphamide single treatment and sequential treatment. Interestingly, while injections of $25 \mathrm{mg} / \mathrm{kg}$ cyclophosphamide on days 27 and 28 after MM injection failed to protect mice, improved survival was observed upon administration of subsequent anti-CD137 mAb treatment (Figure 10, A and B). When given at higher doses $(100 \mathrm{mg} / \mathrm{kg})$, transient protection was observed with cyclophosphamide injections alone (Figure 10C). However, none of the mice receiving cyclophosphamide alone survived beyond day 100, in contrast to mice that received the sequential cyclophosphamide plus anti-CD137 mAb treatment (Figure 10D). Finally, we found that anti-CD137 mAbs improved disease control in mice that had been treated with melphalan, another chemotherapeutic commonly administered to MM patients (Figure 11). Together, these data emphasize the potential of immune stimulation through antiCD137 mAbs to allow long-term survival and suggest that anti-CD137 mAbs might have better therapeutic effect when administered as a consolidation treatment following debulking therapy.

\section{Discussion}

Immune-based therapies hold promise for the treatment of MM (28). Still, the limited clinical activity of PD-1 checkpoint blockade as a single agent (5) and its toxicity when combined with IMiDs (6) underscore the need for improved understanding of responses to immunotherapies in order to define the best timing and combination settings. In this study, we confirmed the high therapeutic potential of anti-CD137 mAbs against MM while also demonstrating the limitations of this treatment. In the $\mathrm{VK}^{*} \mathrm{MYC}$ mouse model of MM, anti-CD137 mAb treatment failed to control advanced disease stages characterized by a high tumor burden and a decline in $\mathrm{BM} \mathrm{CD} 8^{+}$ $\mathrm{T}$ cell numbers. We showed that releasing Treg-mediated immunosuppression or debulking the tumor through chemotherapy restores the efficacy of anti-CD137 mAb treatment at advanced disease stages.

Our data provide further insights into the mechanisms of action of anti-CD137 mAbs against MM. We previously established that in the Vk* MYC model, anti-CD137 mAb therapy requires both $\mathrm{CD}^{+} \mathrm{T}$ cells and NK cells (12). Here, we demonstrated that IFN- $\gamma$ also contributes to the anti-MM effect of anti-CD137 mAbs, a finding that is in agreement with observations made in other tumor models (29). IFN- $\gamma$ released in the context of anti-CD137 mAb therapy might either act directly on MM cells or be necessary for the development of an efficient immune response. Our results suggest that both mechanisms contribute to the anti-MM effect of anti-CD137 mAbs. Indeed, MM tumors grew faster in Ifn$\gamma^{-1-}$ mice, while tumors failed to develop in Ifn $\gamma r^{-1-}$ mice. Given that VK ${ }^{*} \mathrm{MYC}$ cells express functional receptor to IFN- $\gamma$ (data not shown), these data indicate that excess of IFN- $\gamma$ in mice lacking its receptor directly inhibits $\mathrm{MM}$ cell engraftment in the $\mathrm{BM}$. Interestingly, $\mathrm{CD} 8^{+} \mathrm{T}$ cells were required for the protection of Ifn $\gamma^{\prime-}$ mice against MM, but Ifn $\gamma r^{\prime-}$ mice that had been depleted of $\mathrm{CD}^{+} \mathrm{T}$ cells still exhibited increased levels of circulating IFN- $\gamma$ compared with WT mice (data not shown), demonstrating that high circulating levels of IFN- $\gamma$ are not sufficient to control MM in the absence of CD8 ${ }^{+}$ $\mathrm{T}$ cells. Moreover, CD8 ${ }^{+} \mathrm{T}$ cell expansion following anti-CD137 mAb treatment was compromised in both Ifn $\gamma r^{--}$and Ifn $\gamma r^{-1}$ mice, demonstrating that IFN- $\gamma$ signaling is required for the development of efficient $\mathrm{CD}^{+} \mathrm{T}$ cell responses to anti-CD137 mAbs. We established that NK cells constitute the first lymphocyte subset to respond to CD137 stimulation. It is possible that early IFN- $\gamma$ production by NK cells is a prerequisite to $\mathrm{CD}^{+} \mathrm{T}$ cell activation, as suggested by Wilcox et al. (30).

Although the experiments performed in the present study mostly focused on the IFN- $\gamma$ response induced by anti-CD137 mAbs, it should be noted that this therapy is also known for increasing $\mathrm{T}$ cell survival and cytotoxic activity (9). In our model, analysis of CD107a membrane expression indicated that both anti-CD137 mAb treatment and/or a high MM burden triggered $\mathrm{CD} 8^{+} \mathrm{T}$ cell degranulation (data not shown). Given the observation of a nonsignificant trend toward decreased MM burden in Ifn $\gamma^{-1-}$ mice treated with anti-CD137 mAbs, IFN- $\gamma$-independent mechanisms such as perforin/granzyme- or Fas-mediated killing of tumor cells probably contributed to the anti-MM effect of anti-CD137 mAbs.

We observed that NK cell responses to anti-CD137 mAbs were transient and that splenic NK cell numbers were dramatically reduced 1 week after the injection of anti-CD137 mAbs. Several explanations have been proposed for the anti-CD137 mAb-dependent loss of NK cells. Choi et al. suggested a block in NK cell development caused by IFN- $\gamma$ (22). However, in our hands, anti-CD137 mAb treatment depleted NK cells in both Ifn $\gamma^{-1-}$ and Ifn $\gamma^{-1-}$ mice (data not shown). Niu et al. proposed that spleen NK cells traffic to the liver and lung in anti-CD137 mAb-treated mice (24), but we observed decreased NK cell numbers in both 
lung and liver of MM-bearing mice treated with anti-CD137 mAbs (data not shown). The observation that anti-CD137 mAbs deplete NK cells in mice lacking activating Fc receptors (data not shown) ruled out the hypothesized antibody-dependent cellular cytotoxicity. It is possible that, in our system, NK cells undergo activation-induced cell death, as previously described (23).

The present study highlights the ability of MM cells to both induce and suppress immune responses. In mice with low MM burden, we established a positive correlation between the percentages of IFN- $\gamma$-producing $\mathrm{CD}^{+} \mathrm{T}$ cells and tumor burden, indicating that spontaneous $\mathrm{CD} 8^{+} \mathrm{T}$ cell responses are triggered by the presence of MM cells. These data are in agreement with those from Dhodapkar et al. (31), who reported that $\mathrm{T}$ cells freshly isolated from the BM of patients diagnosed with monoclonal gammopathy of unknown significance (MGUS; the premalignant stage that precedes MM) are reactive against autologous premalignant cells. However, we found that, in mice with high MM burden, the correlation between IFN- $\gamma$-producing $\mathrm{CD}^{+} \mathrm{T}$ cells and tumor burden became negative. These data are in agreement with the observation that freshly isolated BM T cells from MM patients present no reactivity against autologous MM cancer cells (32) and suggest that, at advanced disease stages, the tumor becomes suppressive and inhibits the initially triggered spontaneous responses.

Given that immune responses are suppressed as MM grows, it is necessary to define the ability of immunotherapies to induce efficient immune responses in clinically active MM stages. Our data established that even in mice with high tumor burden, T cells respond to CD137 stimulation by proliferating vigorously and secreting high amounts of IFN- $\gamma$. This information highlights the potential of antiCD137 mAbs to reinvigorate $\mathrm{T}$ cell responses and to restore antitumor immunity even at advanced disease stages when $\mathrm{T}$ cells are actively repressed by the tumor. However, in this set of experiments $\mathrm{T}$ cell responses were investigated after a single injection of anti-CD137 mAbs, and we have not ruled out the possibility that a 2 -week anti-CD137 mAb treatment consisting of 4 injections may induce $\mathrm{T}$ cell exhaustion in advanced disease stages. In addition, several other hypotheses could explain why potent $\mathrm{T}$ cell responses to anti-CD137 mAbs did not translate into therapeutic activity in mice with high MM burden. We observed that the production of the immunosuppressive cytokine IL-10 increases as MM burden grows, and this might contribute to repressing T cell responses to anti-CD137 mAbs in vivo. Moreover, at advanced MM stages, we observed a drastic decline in total immune cell numbers in the BM (data not shown). Notably, $\mathrm{CD}^{+} \mathrm{T}$ cell numbers were dramatically reduced in mice with high MM burden prior to anti-CD137 mAb treatment, and the fold increase in $\mathrm{CD}^{+} \mathrm{T}$ cell numbers after CD137 stimulation was smaller at advanced disease stages. We propose that the lack of efficacy of anti-CD137 mAbs at late disease stages is due to the inability of this therapy to expand sufficient numbers of $\mathrm{CD}^{+} \mathrm{T}$ cells, leading to an insufficient $\mathrm{CD} 8 / \mathrm{MM}$ ratio.

Doban et al. (25) have proposed a dynamical model that considers the interactions between tumor cells and resting (i.e., naive) and hunting (i.e., activated) immune cells through predator-prey competition terms. We adapted this model to fit our experimental data and study the interactions between CD8 ${ }^{+} \mathrm{T}$ cells and MM cells in Vk* MYC cell-injected mice. Notably, we introduced a CD8 ${ }^{+} \mathrm{T}$ cell contraction term associated with a new population of exhausted $\mathrm{CD}^{+} \mathrm{T}$ cells; this was necessary for the system to return to steady-state conditions after eradication of the tumor. Moreover, we used delay differential equations (with discrete delays) to account for time delays in $\mathrm{CD}^{+} \mathrm{T}$ cell activation, $\mathrm{CD} 8^{+} \mathrm{T}$ cell contraction, and tumor dormancy. We also incorporated new parameters to distinguish between tumor- and immunotherapy-induced activation of CD8 ${ }^{+}$ $\mathrm{T}$ cells. This new model allowed us to evaluate the impact of various parameters (MM growth rate, $\mathrm{CD} 8^{+}$ $\mathrm{T}$ cell proliferation rate, $\mathrm{CD} 8^{+} \mathrm{T}$ cell activation rate, $\mathrm{CD} 8^{+} \mathrm{T}$ cell killing capacity, MM-immunosuppressive effect) on immunotherapy efficacy. We believe that the present model is suitable for the analysis of immune cell-tumor cell interactions in most cancer types and should provide a useful tool for cancer immunologists.

We found that releasing immunosuppression through Treg depletion increased BM CD8 ${ }^{+} \mathrm{T}$ cell numbers and restored the efficacy of anti-CD137 mAbs against advanced MM disease. Although these findings suggest that immune checkpoint blockade would be efficient in these settings, anti-CD137 mAb in combination with anti-CTLA4 or anti-PD-1 mAbs did not lead to improved efficacy against advanced $\mathrm{Vk}^{*} \mathrm{MYC}$ MM tumors compared with anti-CD137 mAb as a single agent. These results are disappointing given the promising potential of combining CD137 stimulation with PD-1/PD-L1 blockade in solid tumors (33). Nevertheless, it was recently reported that PD-1 blockade abrogates the therapeutic efficacy of anti-CD137 mAbs in the E $\mu$-MYC model of mouse lymphoma (34). In agreement with this report, our data emphasize the need for a better understanding of the underlying immune responses to combi- 
nation therapies to define the specific cancer types and conditions where they might be beneficial. Moreover, we recently identified $\mathrm{T}$ cell immunoreceptor with Ig and ITIM domains (TIGIT) as a dominant negative regulator of $\mathrm{CD}^{+} \mathrm{T}$ cell responses against $\mathrm{MM}(35,36)$. Since TIGIT is expressed at higher levels than PD-1 or CTLA-4 on BM CD8 ${ }^{+} \mathrm{T}$ cells from MM patients (35), we suggest that combination of CD137 costimulation with TIGIT blockade should be explored in MM.

We observed that anti-CD137 mAb treatment improved MM control when administered after chemotherapy with either cyclophosphamide or melphalan. Although low doses of cyclophosphamide are known to deplete Tregs (37), we observed no reduction in Treg numbers in the BM and spleen of mice treated with low-dose cyclophosphamide $(20 \mathrm{mg} / \mathrm{kg}$ ). Since delayed anti-CD137 mAb treatment was also efficient after treatment with high-dose cyclophosphamide or with the myeloablative agent melphalan, we do not think that modulation of Treg responses is instrumental for the success of sequential therapy. Instead, our data suggest that tumor debulking leading to an increased CD8/MM ratio is the main mechanism by which chemotherapy with cyclophosphamide or melphalan restores the efficacy of delayed anti-CD137 mAb treatment.

The identification of biomarkers of responses and the definition of optimal timing is of primary importance for the clinical development of immunotherapies. Here, we showed that M-protein measurement predicts response to anti-CD137 mAb immunotherapy. Therefore, we suggest that anti-CD137 mAbs should be administered to eradicate residual tumor cells after debulking strategies. Accordingly, CD137 costimulation was found to promote long-term survival after autologous stem cell transplantation in the Vk* MYC MM model (38). Collectively, our data provide a rationale for clinical trials to evaluate anti-CD137 mAbs as a consolidation treatment for MM patients with minimal residual disease.

\section{Methods}

Further information can be found in Supplemental Methods, available online with this article.

Mice. All mice used in this study were on a C57BL/6 genetic background. C57BL/6 WT mice were purchased from the Walter and Eliza Hall Institute for Medical Research, bred in house at QIMR Ber-

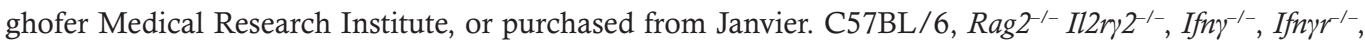
Ifnar ${ }^{\prime-}$, and Foxp3-DTR mice have been previously described (12, 27, 39, 40). Mice were bred and maintained at the QIMR Berghofer Medical Research Institute or in the specific pathogen-free animal facility of the US006 Centre Régional d'Exploration Fonctionnelle et Ressources Expérimentales (CREFRE)INSERM/Université Paul Sabatier (UPS), accredited by the French Ministry of Agriculture (accreditation no. A-31 55508). Mice were used at 8-16 weeks of age.

$V k^{*}$ MYC cell line model. All experiments have been performed with the Vk12653 Vk* MYC cell line as pre-

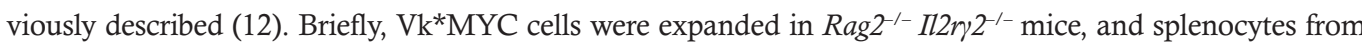

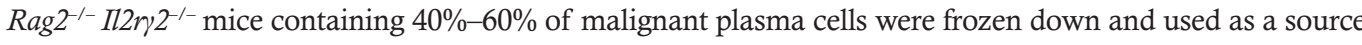
of Vk*MYC MM cells. For Vk*MYC cell challenges, mice were injected i.v. with $2 \times 10^{6}$ live splenocytes

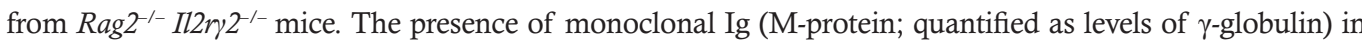
the serum was determined by serum protein electrophoresis (HYDRASYS, Sebia HYDRAGEL). In some experiments, the percentages and numbers of malignant plasma cells (MM cells) in the spleen and BM were analyzed by flow cytometry by gating on $\mathrm{CD} 155^{+} \mathrm{CD} 138^{+} \mathrm{B} 220^{-}$live cells. For survival experiments, mice were monitored over time for external signs of disease, including back leg paralysis, hunched posture, ruffled fur, and swollen abdomen. Sick mice were sacrificed according to instructions from the QIMR Berghofer Medical Research Institute Animal Ethics Committee.

Anti-MM therapy. Mice receiving a 2-week anti-CD137 mAb treatment were injected i.p. with $100 \mu \mathrm{g}$ anti-CD137 mAbs (rat IgG2a, clone 3H3, Bio X Cell) or control rat IgG2a twice a week for 2 weeks. In some experiments, mice received a single i.p. injection of $100 \mu \mathrm{g}$ anti-CD137 mAbs or control rat IgG2a. To deplete Tregs, 250 ng DT (Sigma-Aldrich) was administered i.p. to C57BL/6 FoxP3-DTR mice, as previously described (27); control mice were injected with PBS.

Flow cytometry. Single-cell suspensions were resuspended in FACS buffer containing 2.4G2 (anti-CD16/32) to block Fc receptors. Cell surface staining was performed using the following conjugated mAbs: anti-mouse CD45.2 (clone 104), TCR $\beta$ (clone H57-597), CD4 (clone RM4-5), CD8 $\alpha$ (clone 53-6.7), NK1.1 (clone PK136), NKp46 (clone 29A1.4), B220 (clone RA3-6B2), CD138 (clone 281-2), CD155 (clone 4.24.1), CD62L (clone MEL-14), CD44 (clone IM7), and the live/dead dye Zombie Yellow (BioLegend). For intracellular staining, cells were first surface stained and then fixed and permeabilized with Foxp3/Transcription Factor Fixation/ Fixation kit (eBiosciences) and stained with anti-mouse FoxP3 (clone FJK-16s) or Ki-67 (clone B56). Alterna- 
tively, to measure cytokine production, cells were first cultured for 2 hours with PMA-ionomycin before being surface stained. Then cells were fixed and permeabilized with the BD Cytofix/Cytoperm kit (BD Biosciences) and stained with anti-mouse IFN- $\gamma$ (clone XMG1.2), TNF (clone MP6-XT22), or IL-10 (clone JES5-16E3). All flow cytometry antibodies were purchased from BioLegend or eBioscience. BD Liquid Counting Beads (BD Biosciences) were added to each sample to determine cell numbers. Samples were acquired on an LSRFortessa 4 laser flow cytometer (BD Biosciences) and analyzed with FlowJo version 10 (Tree Star).

Statistics. Statistical analyses were carried out using GraphPad Prism Software, except for the logistic regression and partition tree analyses, which were performed using JMP Pro 14 (SAS Institute). For data presented on a log scale (MM or T cell numbers), statistical analyses were performed on the log-transformed data with the indicated test. Two-sample analyses were performed using a Mann-Whitney $U$ test. Group analyses were performed with a Kruskal-Wallis test followed by Dunn's multiple-comparisons post hoc test. Log-rank test was used for survival analyses. Pearson's $r$ correlation coefficient was calculated to assess correlations between 2 parameters, except for Figure 5C, where data were analyzed with an unconstrained segmental regression using the GraphPad Prism software.

Study approval. All experiments were approved by the QIMR Berghofer Medical Research Institute Animal Ethics Committee or by the local ethics committee (Comité d'Ethique de 1'US 006/CREFRE [C2EA-122]) (Midi-Pyrénées, France), in compliance with French and European regulations on care and protection of laboratory animals.

\section{Author contributions}

CG and MJS are responsible for the study conception and design. CG, ACP, SK, KS, KM, KN, HH, MC, and YY acquired data. CG, KN, ACP, DB, LM, and MJS analyzed and interpreted data. GH and DS were responsible for statistical analysis, and $\mathrm{CG}, \mathrm{DB}, \mathrm{AID}$, and $\mathrm{ML}$ were responsible for in silico analyses. CG drafted the manuscript, and DB, KN, SV, MWLT, PLB, MC, GRH, and MJS provided critical revision and editing. MWLT, GRH, LM, and MJS supervised.

\section{Acknowledgments}

The authors thank Liam Town and Kate Elder for breeding, genotyping, maintenance, and care of the mice used in this study. We thank the animal house and flow cytometry facilities at QIMR Berghofer Medical Research Institute; and members of Immunology in Cancer and Infection Laboratory, the Cancer Immunoregulation and Immunotherapy Laboratory, and the Bone Marrow Transplantation Laboratory, as well as Christian Engwerda for helpful suggestions and discussion. We thank Kestutis Barkauskas for valuable help in developing the in silico model. This work was funded by a Priority-driven Collaborative Cancer Research Scheme grant (number 1122183) co-funded by Cancer Australia, Cure Cancer Australia and Can Too Foundation and a QIMR Berghofer Seed Grant awarded to CG; and by a National Health and Medical Research Council of Australia (NHMRC) Program Grant 1132519 and Project Grant 1098960 to MJS and MWLT. CG was supported by NHMRC Early Career Fellowship 1107417. ACP was supported by a grant from Ligue nationale contre le cancer. HH was supported by a University of Queensland (UQ) International Postgraduate Research Scholarship, a UQ Australian Postgraduate Award, and QIMR Berghofer Top-Up awards. KN was supported by the Naito Foundation and NHMRC Project Grant (number 1159593). GRH was supported by a NHMRC Program Grant 1071822 and Research Fellowship 1107797. MJS was supported by Senior Principal Research Fellowship 1078671.

Address correspondence to: Camille Guillerey, Cancer Immunotherapies Laboratory, Mater Research Institute, The University of Queensland, Translational Research Institute, Woolloongabba, Brisbane, Queensland, Australia. Phone: 61.7.3443.7519; Email: camille.guillerey@mater.uq.edu.au.

1. Kumar SK, et al. Multiple myeloma. Nat Rev Dis Primers. 2017;3:17046.

2. Rasche L, Weinhold N, Morgan GJ, van Rhee F, Davies FE. Immunologic approaches for the treatment of multiple myeloma. Cancer Treat Rev. 2017;55:190-199.

3. Touzeau C, Moreau P, Dumontet C. Monoclonal antibody therapy in multiple myeloma. Leukemia. 2017;31(5):1039-1047.

4. D'Agostino M, Boccadoro M, Smith EL. Novel immunotherapies for multiple myeloma. Curr Hematol Malig Rep. 2017;12(4):344-357.

5. Rosenblatt J, Avigan D. Targeting the PD-1/PD-L1 axis in multiple myeloma: a dream or a reality? Blood. 2017;129(3):275-279.

6. Badros A, et al. Pembrolizumab, pomalidomide, and low-dose dexamethasone for relapsed/refractory multiple myeloma. Blood. 
2017;130(10):1189-1197.

7. Sanmamed MF, et al. Agonists of co-stimulation in cancer immunotherapy directed against CD137, OX40, GITR, CD27, CD28, and ICOS. Semin Oncol. 2015;42(4):640-655.

8. Bartkowiak T, Curran MA. 4-1BB Agonists: multi-potent potentiators of tumor immunity. Front Oncol. $2015 ; 5: 117$.

9. Chester C, Sanmamed MF, Wang J, Melero I. Immunotherapy targeting 4-1BB: mechanistic rationale, clinical results, and future strategies. Blood. 2018;131(1):49-57.

10. Teijeira A, et al. Mitochondrial morphological and functional reprogramming following CD137 (4-1BB) costimulation. Cancer Immunol Res. 2018;6(7):798-811.

11. Aznar MA, et al. CD137 (4-1BB) Costimulation modifies DNA methylation in CD8. Cancer Immunol Res. 2018;6(1):69-78.

12. Guillerey C, et al. Immunosurveillance and therapy of multiple myeloma are CD226 dependent. J Clin Invest. 2015;125(5):2077-2089.

13. Murillo O, et al. Therapeutic antitumor efficacy of anti-CD137 agonistic monoclonal antibody in mouse models of myeloma. Clin Cancer Res. 2008;14(21):6895-6906.

14. Makkouk A, Chester C, Kohrt HE. Rationale for anti-CD137 cancer immunotherapy. Eur J Cancer. 2016;54:112-119.

15. Sánchez-Paulete AR, et al. Cancer immunotherapy with immunomodulatory anti-CD137 and anti-PD-1 monoclonal antibodies requires BATF3-dependent dendritic cells. Cancer Discov. 2016;6(1):71-79.

16. Segal NH, et al. Results from an integrated safety analysis of urelumab, an agonist anti-CD137 monoclonal antibody. Clin Cancer Res. 2017;23(8):1929-1936.

17. Tolcher AW, et al. Phase Ib study of utomilumab (PF-05082566), a 4-1BB/CD137 agonist, in combination with pembrolizumab (MK-3475) in patients with advanced solid tumors. Clin Cancer Res. 2017;23(18):5349-5357.

18. Segal NH, et al. Phase I study of single-agent utomilumab (PF-05082566), a 4-1BB/CD137 agonist, in patients with advanced cancer. Clin Cancer Res. 2018;24(8):1816-1823.

19. Guillerey C, Nakamura K, Vuckovic S, Hill GR, Smyth MJ. Immune responses in multiple myeloma: role of the natural immune surveillance and potential of immunotherapies. Cell Mol Life Sci. 2016;73(8):1569-1589.

20. Dosani T, et al. Host-related immunodeficiency in the development of multiple myeloma. Leuk Lymphoma. 2018;59(5):1127-1132.

21. Ascierto PA, Simeone E, Sznol M, Fu YX, Melero I. Clinical experiences with anti-CD137 and anti-PD1 therapeutic antibodies. Semin Oncol. 2010;37(5):508-516.

22. Choi BK, et al. Peripheral 4-1BB signaling negatively regulates NK cell development through IFN-gamma. J Immunol. 2010;185(3):1404-1411.

23. Lee SW, Salek-Ardakani S, Mittler RS, Croft M. Hypercostimulation through 4-1BB distorts homeostasis of immune cells. J Immunol. 2009;182(11):6753-6762.

24. Niu L, et al. Cytokine-mediated disruption of lymphocyte trafficking, hemopoiesis, and induction of lymphopenia, anemia, and thrombocytopenia in anti-CD137-treated mice. J Immunol. 2007;178(7):4194-4213.

25. Doban AI, Lazar M. A switching control law approach for cancer immunotherapy of an evolutionary tumor growth model. Math Biosci. 2017;284:40-50.

26. Kawano Y, et al. Blocking IFNAR1 inhibits multiple myeloma-driven Treg expansion and immunosuppression. J Clin Invest. 2018;128(6):2487-2499.

27. Liu J, et al. Assessing immune-related adverse events of efficacious combination immunotherapies in preclinical models of cancer. Cancer Res. 2016;76(18):5288-5301.

28. Köhler M, et al. Current developments in immunotherapy in the treatment of multiple myeloma. Cancer. 2018;124(10):2075-2085.

29. Wilcox RA, et al. Impaired infiltration of tumor-specific cytolytic T cells in the absence of interferon-gamma despite their normal maturation in lymphoid organs during CD137 monoclonal antibody therapy. Cancer Res. 2002;62(15):4413-4418.

30. Wilcox RA, Tamada K, Strome SE, Chen L. Signaling through NK cell-associated CD137 promotes both helper function for CD8+ cytolytic T cells and responsiveness to IL-2 but not cytolytic activity. J Immunol. 2002;169(8):4230-4236.

31. Dhodapkar MV, Krasovsky J, Osman K, Geller MD. Vigorous premalignancy-specific effector T cell response in the bone marrow of patients with monoclonal gammopathy. J Exp Med. 2003;198(11):1753-1757.

32. Dhodapkar MV, Krasovsky J, Olson K. T cells from the tumor microenvironment of patients with progressive myeloma can generate strong, tumor-specific cytolytic responses to autologous, tumor-loaded dendritic cells. Proc Natl Acad Sci U S A. 2002;99(20):13009-13013.

33. Pérez-Ruiz E, Etxeberria I, Rodriguez-Ruiz ME, Melero I. Anti-CD137 and PD-1/PD-L1 antibodies en route toward clinical synergy. Clin Cancer Res. 2017;23(18):5326-5328.

34. McKee SJ, Doff BL, Soon MS, Mattarollo SR. Therapeutic efficacy of 4-1BB costimulation is abrogated by pd-1 blockade in a model of spontaneous B-cell lymphoma. Cancer Immunol Res. 2017;5(3):191-197.

35. Guillerey C, et al. TIGIT immune checkpoint blockade restores CD8. Blood. 2018;132(16):1689-1694.

36. Minnie SA, et al. Myeloma escape after stem cell transplantation is a consequence of T-cell exhaustion and is prevented by TIGIT blockade. Blood. 2018;132(16):1675-1688

37. Ahlmann M, Hempel G. The effect of cyclophosphamide on the immune system: implications for clinical cancer therapy. Cancer Chemother Pharmacol. 2016;78(4):661-671.

38. Vuckovic S, et al. Bone marrow transplantation generates $\mathrm{T}$ cell-dependent control of myeloma in mice. J Clin Invest. 2019;129(1):106-121.

39. Starr R, et al. SOCS-1 binding to tyrosine 441 of IFN-gamma receptor subunit 1 contributes to the attenuation of IFN-gamma signaling in vivo. J Immunol. 2009;183(7):4537-4544.

40. Hwang SY, et al. A null mutation in the gene encoding a type I interferon receptor component eliminates antiproliferative and antiviral responses to interferons alpha and beta and alters macrophage responses. Proc Natl Acad Sci U S A. 1995;92(24):11284-11288. 